\title{
NISTIR 7135
}

\section{Final Report for:}

EPA: IAG No. DW-13-93903501-0 Expanding a tool for predicting chloride diffusivity in concrete so it can be used by manufacturers to evaluate the durability of concrete made with blended cements. Part I: Characterizing blended cement materials.

\author{
X. Feng ${ }^{*}$, NIST and Northwestern University \\ E.J. Garboczi, J.W. Bullard, D.P. Bentz, K.A. Snyder, and P.E. Stutzman, NIST \\ T.O. Mason, Northwestern University
}

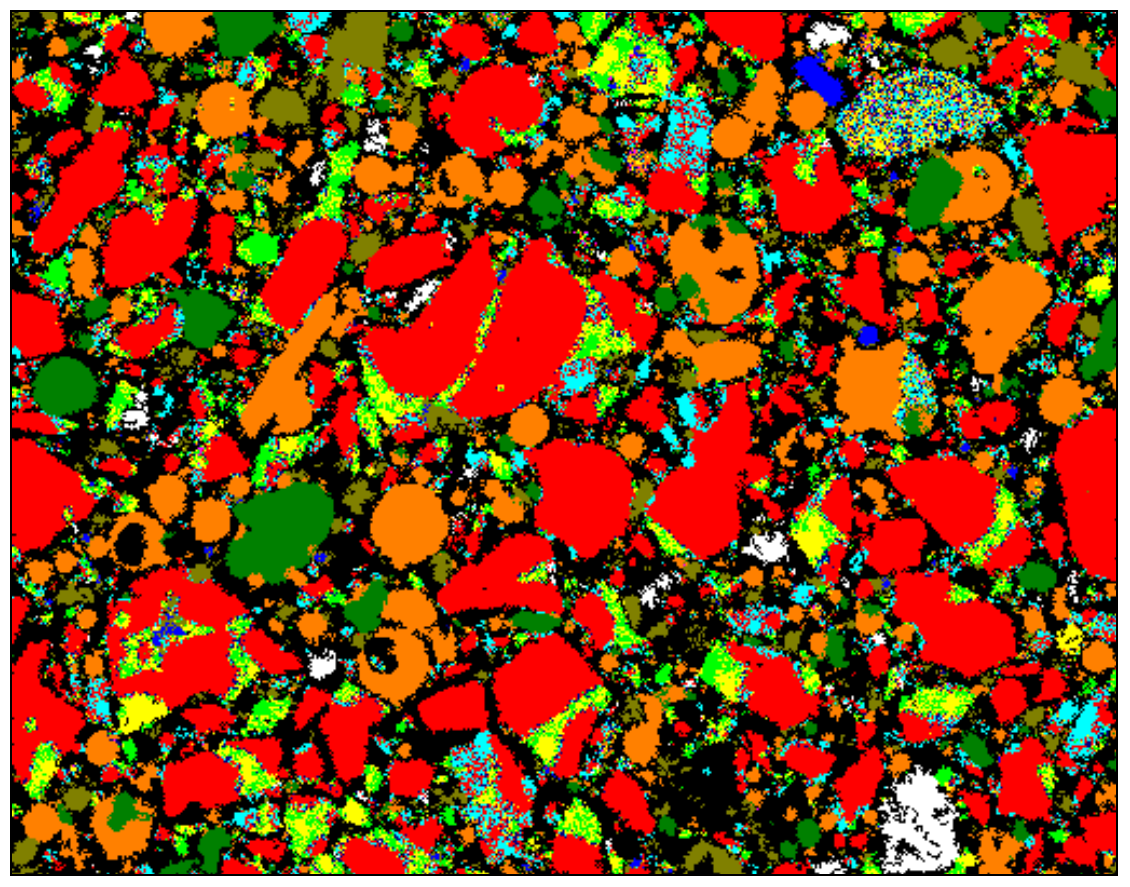



NISTIR 7135

\section{Final Report for:}

EPA: IAG No. DW-13-93903501-0 Expanding a tool for predicting chloride diffusivity in concrete so it can be used by manufacturers to evaluate the durability of concrete made with blended cements. Part I: Characterizing blended cement materials.

\section{Feng ${ }^{*}$, NIST and Northwestern University}

E.J. Garboczi, J.W. Bullard, D.P. Bentz, K.A. Snyder, and P.E. Stutzman, NIST

T.O. Mason, Northwestern University

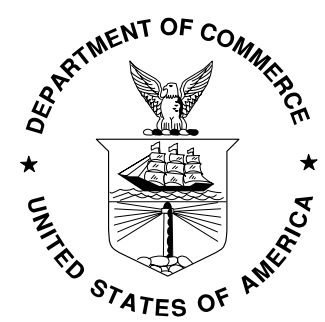

U.S. DEPARTMENT OF COMMERCE

Donald L. Evans, Secretary TECHNOLOGY ADMINISTRATION

Phillip J. Bond, Under Secretary of Commerce for Technology 



\section{Final Report for:}

EPA: IAG No. DW-13-93903501-0 Expanding a tool for predicting chloride diffusivity in concrete so it can be used by manufacturers to evaluate the durability of concrete made with blended cements. Part I: Characterizing blended cement materials.

by

X. Feng ${ }^{*}$, NIST and Northwestern University

E.J. Garboczi, J.W. Bullard, D.P. Bentz, K.A. Snyder, and P.E. Stutzman, NIST T.O. Mason, Northwestern University

Cover: Processed scanning electron microscopic image of the fly ash-blended cement (256 $\mu \mathrm{m}$ by $200 \mu \mathrm{m}$ ) studied in this report. The orange particles are fly ash, and the rest are cement constituents. Some of the orange fly ash particles are not particularly round, as is usual for fly ash, which may be a result of the fly ash-cement intergrinding process.

\footnotetext{
${ }^{*}$ Present address: Department of Civil Engineering, University of New Brunswick, New Brunswick, Canada
} 


\section{Table of Contents}

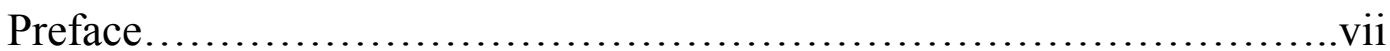

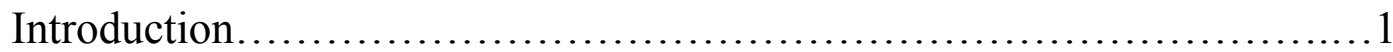

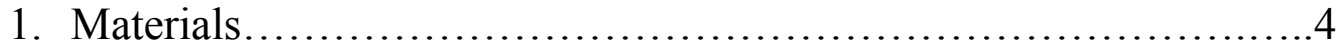

2. Paste preparation...............................................

3. Detailed experimental procedures and results...................... 7

3.1 Chemical shrinkage........................................... 7

3.2 Degree of hydration by LOI and SEM......................... 10

3.3 Pore solution press and conductivity measurement.................11

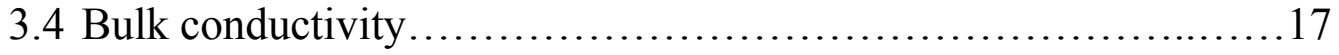

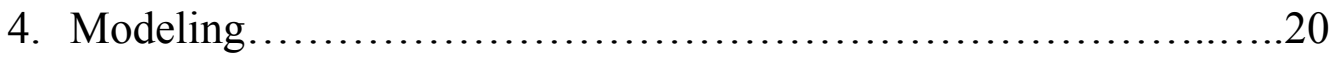

4.1 3-D microstructures for cement clinkers........................20

4.2 Degree of hydration and fly ash reaction modeling.................22

4.3 Conductivity modeling.........................................26

4.3.1 Determination of the conductivity of regular C-S-H for T-1 and T-L cements..................................26

4.3.2 Results of conductivity modeling for $\mathrm{T}-1$ cement...............26

4.3.3 Results of conductivity modeling for T-L cement..............28

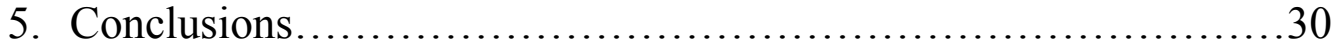

6. Acknowledgements......................................... 30

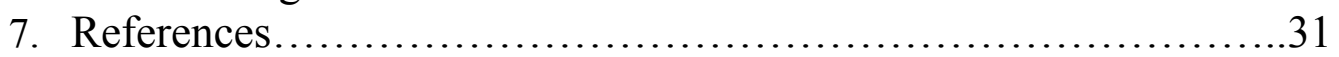




\section{Preface: The Virtual Cement and Concrete Testing Laboratory and the Nature of This Project}

The Virtual Cement and Concrete Testing Laboratory (VCCTL) Consortium was formed in January 2001. The overall goal of the consortium is to develop a virtual testing system that will reduce the amount of physical cement and concrete testing needed and expedite the research and development process in the cement and concrete industry. This will result in substantial time and cost savings to all aspects of the concrete construction industry. Headquartered in the Building and Fire Research Laboratory (BFRL) at the National Institute of Standards and Technology (NIST), at present, June, 2004, the consortium consists of two NIST laboratories: the Building and Fire Research Laboratory (BFRL) and the Information Technology Laboratory (ITL), and nine industrial members: (cement companies) Holcim (US) Inc. and the Portland Cement Association (PCA); (chemical admixture companies) Master Builders Technologies Inc. (MBT), W.R. Grace \& Co, and Sika Technology AG; (aggregate companies) International Center for Aggregates Research (ICAR); (ready-mixed concrete companies) National Ready-Mixed Concrete Association (NRMCA); and the French and German portland cement associations, Association Technique de l'Industrie des Liants Hydrauliques (ATILH), and Verein Deutscher Zementwerke e.V. (VDZ). In the United States, we estimate that $80 \%$ of the cement market, 90 $\%$ of the chemical admixture market, $75 \%$ of the aggregate market, and $80 \%$ of the readymixed concrete market are represented in the VCCTL consortium either through direct participation or through the participation of the relevant trade association.

The VCCTL software package consists of fundamental models of microstructure formation and physical property prediction for cement-based materials (cement paste, mortar, and concrete). But without meticulous characterization of the starting materials, it is practically impossible to formulate fundamental microstructure models of the hydration and properties of a cement paste, mortar, or concrete. One of the signature features and strengths of the VCCTL cement hydration model is its incorporation of microstructural information with unprecedented levels of detail. Proper characterization of cement-based materials is not a trivial task. The starting powders typically consist of a wide distribution of particle sizes, each particle of which is composed of multiple phases with variable chemical compositions. Many products of hydration are amorphous or poorly crystalline, and these may be finely intermixed. An additional complication is that some microstructural characteristics have not been rigorously defined. In some cases it has not been possible even to properly calibrate measurements, like those of particle size distribution (PSD), because of the absence of an accepted reference material or standard methodology.

Recognizing the critical importance of materials characterization for predictions of microstructure development, physical properties, and durability, the consortium has continually sought to achieve greater accuracy and detail in these types of measurements, and to supply robust, calibrated measurement techniques where those have been lacking. Doing this for wastestream materials that are often added to concrete to improve performance and reduce environmental waste generation, like fly ash or blast-furnace slag, is an especially difficult task. This report summarizes a project that dealt with the characterization of a fly ash and fly-ash 
blended cement material, so that these could be incorporated into the VCCTL software. The information generated from this project will be transferred to the members of the consortium, who represent all parts of the concrete materials community - cement production, chemical admixtures, aggregates, and ready-mixed concrete manufacture. Other members of the cement and concrete industry are welcome to join the VCCTL consortium, to take advantage of this software. Eventually, all the VCCTL software will be publicly accessible, but since new features developed by the consortium are not released to the public for three years, joining the VCCTL consortium will allow quicker access to the software (for more information, contact jeffrey.bullard@nist.gov).

Products of this partially EPA-funded project include: a method for predicting the conductivity of pore solutions where the concentration of $[\mathrm{Na}]^{+}$and $[\mathrm{K}]^{+}$ions are known, unique experimental data on the hydration of cement and the consumption of fly ash in a fly ash blended cement, experimental data on the electrical conductivity of blended cement pastes made from these materials, and model modifications that allow for more quantitative modeling of blended cement hydration and microstructure formation. We are pleased that this project has turned out products that will allow much greater progress in the future in the area of modeling blended cements.

A link is currently being explored between VCCTL, which is materials science-based and oriented towards performance predictions and the BEES (Building for Environmental and Economic Sustainability) software (found at http://www.bfrl.nist.gov/oae/software/bees.html). This link has not been developed enough to be able to described in this report, however. BEES was developed by the NIST (National Institute of Standards and Technology) Building and Fire Research Laboratory, with support from the United States EPA Environmentally Preferable Purchasing Program, to be a powerful technique for selecting cost-effective, environmentallypreferable building products. Linking VCCTL with BEES will give an economic and environmental component that will add to the power of physical performance prediction.

BEES measures the environmental performance of building products by using the life-cycle assessment approach specified in ISO 14000 standards. All stages in the life of a product are analyzed: raw material acquisition, manufacture, transportation, installation, use, and recycling and waste management. Economic performance is measured using the ASTM standard life-cycle cost method, which covers the costs of initial investment, replacement, operation, maintenance and repair, and disposal. Environmental and economic performance are combined into an overall performance measure using the ASTM standard for Multi-Attribute Decision Analysis. For the entire BEES analysis, building products are defined and classified according to the ASTM standard classification for building elements known as UNIFORMAT II. 


\section{Introduction}

The models developed by NIST to predict the microstructure and ionic diffusivity of cementbased materials require experimental information in order to operate successfully. This information is not for providing empirical fits, but is for (1) measuring the fundamental properties of materials needed to accurately simulate the microstructural development, and for (2) validating model predictions of ionic diffusivities. The project summarized in this report is the Environmental Protection Agency (EPA) project on a fly ash (FA) blended cement material. A similar project on a blast furnace slag material, partially funded by the Center for Advanced Cement-Based Materials (ACBM), was simultaneously carried out in one experimental program. Since both programs were small monetarily (and had to be supplemented by NIST funds), this also allowed a single post-doctoral researcher to be hired to do both sets of work simultaneously. This report, however, only summarizes the work on a fly ash blended cement, as that was the goal of the EPA funding. The title states "Part I," since there is clearly more work needed, as will be made clear throughout the report and in the conclusions.

The EPA project, "Expanding a tool for predicting chloride diffusivity in concrete so it can be used by manufacturers to evaluate the durability of concrete made with blended cements," grew out of the EPA ClimateWise program. This program at EPA was working with cement manufacturers to help encourage control of $\mathrm{CO}_{2}$ emissions. Cement manufacturers have been pursuing the option of using fly ash as a replacement for some of the portland cement in concrete. By partially funding the experimental work needed to help incorporate and test the use of a fly ash in the Virtual Cement and Concrete Testing Laboratory (VCCTL), EPA would help encourage the expanded use of fly ash by users of the VCCTL software. A secondary goal of the project was to compare a cement interground with a fly ash at the cement plant with the same cement and same fly ash simply mixed in the laboratory. The term "a fly ash" is used rather than "fly ash," since every fly ash differs from each other. Characterizing a single fly ash does not finish the job for all the classes of fly ash found across the country. The ASTM fly ash classifications, class $\mathrm{C}$ and class $\mathrm{F}$, are very generic, so that just stating that a fly ash material is class $\mathrm{F}$, for example, does not in any way completely characterize its properties when used in a cement system. The challenge of characterizing fly ashes across the United States so that they can be used reliably is an outstanding problem.

Simulating the hydration of portland cement requires detailed knowledge of cement chemistry, and of the chemical and physical makeup of the portland cement being considered. Detailed work to gather this information has been done in the past for portland cement [1]. To incorporate a new material into the model requires the same kind of information on the identity and density of products and the details of the chemical interactions with portland cement constituents. Some of this information for a fly ash was obtained in earlier work [2,3], although some new information had to be obtained for this study. In particular, chemical shrinkage measurements and degree of hydration measurements were made in this study to understand each material's reactions with water and to check with the model, since the fly ash part of CEMHYD3D had not been thoroughly validated before.

It has recently been shown that the rate of ionic transport under diffusion and electrical field gradients can be determined by two parameters - the porosity, $\phi$, and the formation factor, $\mathrm{F}$, 
along with information about the concentration of all types of ions in the water-filled pore space [4-6]. The formation factor is defined simply by the following - for a porous material, assume that the pore space is totally evacuated, without altering the solid part of the material, which has zero conductivity. Fill the pores with a fluid of some known conductivity, $\sigma_{\mathrm{f}}$, again without changing the solid part at all. Measure the bulk conductivity, $\sigma_{\mathrm{b}}$, assuming that the material is uniform. Just from stereology alone $[7,8]$, the value of $\sigma_{\mathrm{b}}$ is at most $\sigma_{\mathrm{b}}=\phi \sigma_{\mathrm{f}}$, and is usually less due to the tortuosity of the pore space $[7,8]$. The ratio $F=\sigma_{\mathrm{f}} / \sigma_{\mathrm{b}}$ is then defined as the formation factor, and is always greater than unity. Using these two parameters, $F$ and $\phi$, along with knowledge of other ion concentrations in the pore space, the entire ionic transport response can be determined $[4,5]$.

$F$ is defined by the above thought experiment. In principle, it can be experimentally determined in cement paste, with some measure of uncertainty, measuring $\sigma_{\mathrm{f}}$ by pressing out the pore solution and measuring the bulk conductivity of a companion sample with nominally the same pore solution. Their ratio then gives the value of $F$. This is the procedure carried out in this paper. There is some experimental uncertainty, as one is not quite sure that one is not changing the pore fluid by causing some pressure-induced dissolution. Also, the amount of pore fluid so expressed is small, leading to the possibility of statistical fluctuations. In fact, it was found as a result of this experimental work that the ionic concentration in the expressed cement paste pore solutions was systematically too high, above even an estimate of the maximum concentration possible. Upon review of the literature, this problem was found in other studies as well. Therefore, we concentrated on only comparing bulk conductivities as predicted by the model to those measured by experiment, as will be described later.

The use of mineral admixtures like fly ash (FA) and ground granulated blast furnace slag (GGBFS) is known to change ionic transport properties. The formation factors of cement pastes with these materials have not, however, been measured before. In order to fundamentally understand ionic transport in these materials, the value of $F$ is needed. For example, a popular test called the Rapid Chloride Permeability Test only measures the bulk resistance (reciprocal of conductance), and so cannot distinguish between materials that alter the pore solution conductivity and materials that alter the pore space characteristics [6]. As was mentioned above, and as will be detailed later, it proved not possible to accurately measure the formation factor of the materials used in this study, so that only the bulk conductivity was compared to model predictions. As the bulk electrical conductivity is a direct analogue of the ionic diffusivity, this is also an important transport parameter and gives insight into what the fly ash does to the microstructure.

The CEMHYD3D model, also as embodied in the VCCTL consortium software [1,9], can predict cement paste microstructure and compute the value of F. In the year 2001 version, the effect on the microstructure of mineral admixtures like FA and slag could also be simulated to some approximation. There were, however, no quantitative measures of the degree of reaction vs. time of the mineral admixtures and measurements of $\mathrm{F}$ against which to compare the predictions of the model and check for any systematic errors. A recent result coming from the present project, using scanning electron microscopy-based point counting, allowed 
measurements to be made of the degree of reaction of FA and GGBFS, along with portland cement, as a function of time [10]. These measurements, along with a new model capability to predict the pore solution concentrations and thus the pore solution conductivity, allow one finally to check the model's predictions when FA is present along with portland cement. The comparison with these data highlighted several shortcomings in the model. Modifications that were made to correct these limitations are also briefly described in this report.

What follows first is a detailed listing of experimental procedures, experimental data, and graphs showing that data. These experimental results pointed out some inadequacies in our hydration model, as regards mainly to fly ash. New model results are then used to compare to the experimental data, showing that the models give generally accurate results for experimental parameters, allowing one, with some degree of confidence, to replace experiments with models. 


\section{Materials}

An ASTM Type I Portland cement, provided by Holcim* (designated as T-1); one blended cement (designated as T-1P) made with $80 \% \mathrm{~T}-1$ cement and $20 \%$ fly ash, interground by a Holcim cement plant; and the same fly ash, also supplied by Holcim, were selected in the current study. The Blaine surface area for cements T-1 and T-1P were $343 \mathrm{~m}^{2} / \mathrm{kg}$ and $400 \mathrm{~m}^{2} / \mathrm{kg}$, respectively (uncertainty of $1 \%$ ). The chemical compositions of the materials used are given in Table 1. The particle size distributions of T-1 and T-1P are shown in Figure 1, as measured by laser diffraction and numerically processed, so that the point at $1 \mu \mathrm{m}$ includes the mass of all particles with particle size less than $1 \mu \mathrm{m}$, the point at $3 \mu \mathrm{m}$ includes the mass of all particles with particle size between 1 and $3 \mu \mathrm{m}$, etc. Figure 1 indicates that T-1P is finer than T-1, probably because of the extra intergrinding carried out at the cement plant to adequately blend the fly ash and portland cement. In cement $\mathrm{T}-1 \mathrm{P}$, the particle size measurement does not distinguish between the cement and fly ash particles, so we do not know how the fly ash and the cement separately contribute to the different parts of the size distribution. The cement particle size distribution is an important piece of information necessary for understanding how a cement will perform in practice, and must be measured quite carefully in order to obtain valid results [11].

It should be emphasized again that this characterization work was done for a single fly ash material. In general, all fly ashes are different from each other. It may be, that if this kind of characterization was done for a broad range of fly ash materials, trends would be seen so that fly ash performance could be related quantitatively to fly ash chemical composition and particle microstructure and size distribution.

Table 1. Chemical Compositions of Cement and the fly-ash used (mass fraction in percent, uncertainty in any number in table is about \pm 0.1 )

\begin{tabular}{|c|c|c|c|}
\hline & T-1 & T-1P & Fly ash \\
\hline $\mathrm{SiO}_{2}$ & 20.1 & 29.8 & 61.3 \\
\hline $\mathrm{Al}_{2} \mathrm{O}_{3}$ & 5.6 & 9.26 & 19.4 \\
\hline $\mathrm{Fe}_{2} \mathrm{O}_{3}$ & 2.5 & 3.32 & 4.5 \\
\hline $\mathrm{CaO}$ & 64.7 & 53.5 & 9.1 \\
\hline $\mathrm{MgO}$ & 0.8 & 1.11 & 2.3 \\
\hline $\mathrm{SO}_{3}$ & 3.4 & 3.19 & 0.2 \\
\hline $\mathrm{K}_{2} \mathrm{O}$ & 0.76 & 0.84 & 1.06 \\
\hline $\mathrm{Na} 2 \mathrm{O}$ & 0.14 & 0.19 & 0.3 \\
\hline L.O.I. & 1.2 & 1.07 & 0.1 \\
\hline
\end{tabular}

\footnotetext{
* Certain commercial equipment and/or materials are identified in this report in order to adequately specify the experimental procedure. In no case does such identification imply recommendation or endorsement by the National Institute of Standards and Technology, nor does it imply that the equipment and/or materials used are necessarily the best available for the purpose.
} 


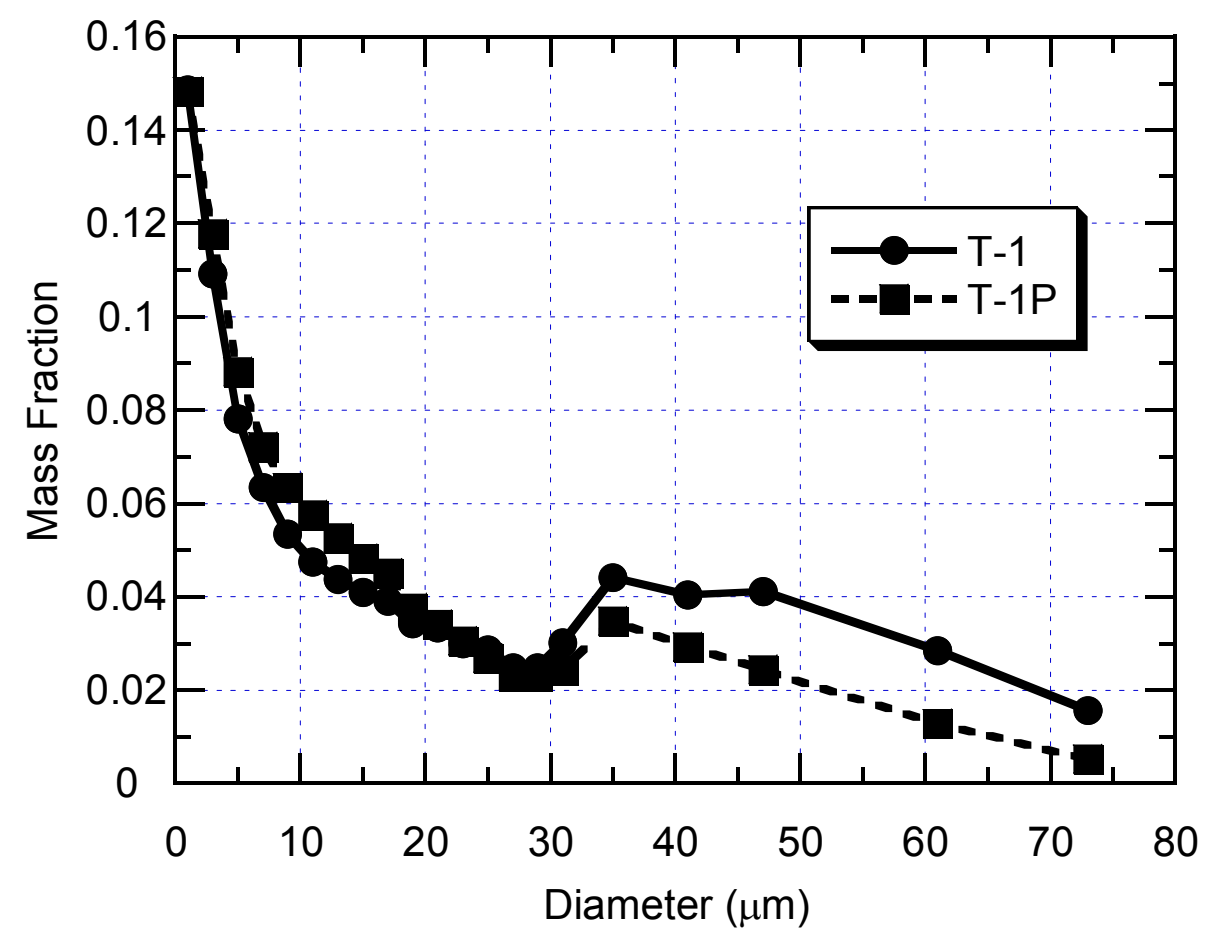

Figure 1. Differential particle size distributions of T-1 and T-1P cements.

\section{Paste preparation}

A fly ash blended cement designated as T-L, similar to T-1P blended cement, also consisting of $20 \%$ (mass fraction) fly ash and $80 \% \mathrm{~T}-1$ cement, was mixed in the laboratory. The purpose to make this T-L cement was an attempt to see any differences in properties obtained between intergrinding a blended cement at the cement plant vs. simply adding fly ash in the laboratory or at a ready-mix plant. When making the blended cement pastes, the solid materials were premixed in a large beaker and then added to the mixing bowl with the water needed, to obtain a homogeneous paste. Overall, six different kinds of cement pastes were studied, three types (T-1, T-1P, T-L) and two w/s ratios, 0.4 and 0.5 . "w/s" means the ratio of the mass of water to the mass of solid materials (cement, fly ash, etc.) used in a particular mix, while "w/c" is defined the same way but where the solid materials are portland cement only.

Before substantial research could progress and samples be made, the bleeding characteristics of each cement needed to be checked. It is very hard to control the w/c ratio in a sample that bleeds heavily (separation of water and cement, instead of staying intimately mixed). The bleeding properties of the three cements are given in Table 2. The uncertainty in these measurements is about $1 \%$, as measurement of mass is very precise. The T-1 cement pastes have the largest bleeding capacity at any w/c tested, which means adding fly ash in cement can significantly 
improve the bleeding properties of cement pastes. Simply blending in fly ash (T-L) improved the bleeding properties somewhat. The T-1P cement, interground at the cement plant, has the smallest bleeding capacity of all three cements, clearly showing the benefits of extra grinding at the cement plant. Note that the T-1P cement had finer particles, and therefore a larger surface area, which means it can "hold on" to water more effectively, thus reducing bleeding.

Table 2. Bleeding capacities ( $\mathrm{mL} / \mathrm{g}$ binder) of cement (1\% uncertainty)

\begin{tabular}{|c|c|c|c|}
\hline $\mathrm{w} / \mathrm{s}$ & $\mathrm{T}-1$ & $\mathrm{~T}-1 \mathrm{P}$ & $\mathrm{T}-\mathrm{L}$ \\
\hline 0.3 & 0.40 & 0.06 & 0.52 \\
\hline 0.35 & 1.42 & 1.16 & 1.57 \\
\hline 0.4 & 2.69 & 1.62 & 2.03 \\
\hline 0.45 & 4.75 & 2.42 & 3.39 \\
\hline
\end{tabular}

Based on the bleeding test results, at the first stage of the project, 0.3 and $0.45 \mathrm{w} / \mathrm{s}$ ratios were chosen to be used for further study for the two blended cement systems. The $0.3 \mathrm{w} / \mathrm{s}$ samples did not require any special treatment, as their bleeding was minimal. However, when we progressed to making samples for conductivity measurements, we found many air bubbles were trapped when casting paste samples at $\mathrm{w} / \mathrm{s}=0.3$, which of course made determining the true conductivity difficult to impossible. Therefore, the w/s ratios studied were chosen to be 0.4 and 0.5 . In order to prevent substantial bleeding at these $\mathrm{w} / \mathrm{s}$ ratios and to also effectively eliminate entrapped air bubbles, house vacuum was employed during the mixing and casting processes, as well as a vibration table during casting (Fig. 2). The samples were cast in sealed plastic molds and slowly rotated on a roller for $5 \mathrm{~h}$. By constantly changing the orientation of the samples with respect to the direction of gravity, bleeding was minimized. After this, the pastes were kept in the molds and put in sealed plastic bags and maintained at $20{ }^{\circ} \mathrm{C}$ and $100 \% \mathrm{RH}$ until the testing age was reached.

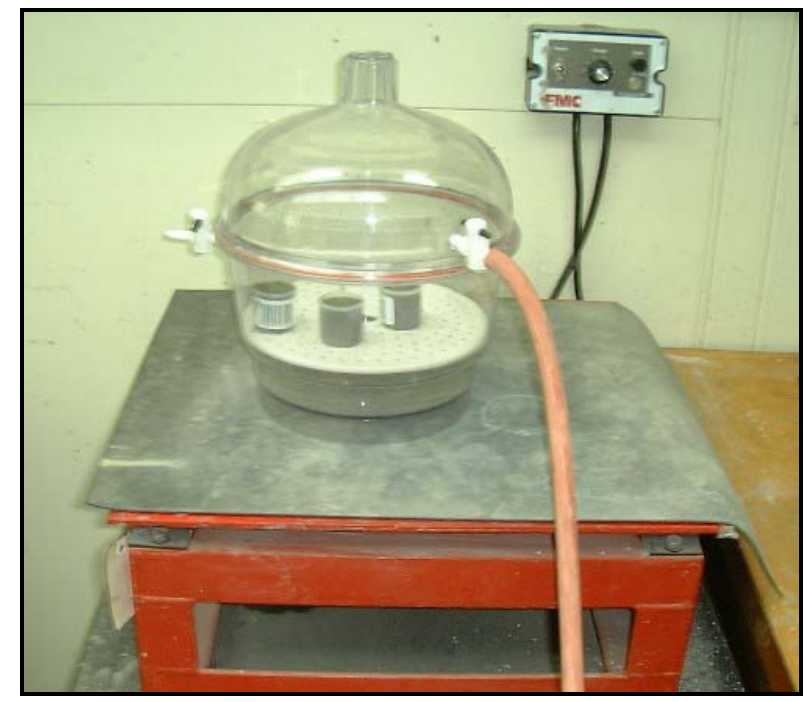

Figure 2. House vacuum container and vibrator used in paste preparation 


\section{Detailed experimental procedures and results}

\subsection{Chemical shrinkage}

Cement pastes were prepared for chemical shrinkage tests. The water to binder mass ratio was controlled at $\mathrm{w} / \mathrm{s}=0.3$. This is lower than is typically used in the field, but is sometimes used for high performance concrete. Cement and the needed water were mixed in the mixer as specified in ASTM C305 (C305-99e1 Standard Practice for Mechanical Mixing of Hydraulic Cement Pastes and Mortars of Plastic Consistency). Pastes were then placed in glass vials, and $1 \mathrm{~mL}$ of limewater was placed on top of the paste to minimize the leaching of calcium hydroxide from the paste. The vials were filled to the top using vegetable oil, to keep out air. Rubber stoppers with $0.01 \mathrm{~mL}$ graduated cylinders encased in the centers were used to seal the vials. This experimental arrangement was placed in a water bath at a temperature of $25^{\circ} \mathrm{C}$. Two replicate specimens were prepared using the same paste. The consumption of water could be followed by the lowering of the water/vegetable oil meniscus in the graduated cylinders. The uncertainty in these measurements is estimated to be about $10 \%$.

Results are shown in Figs. 3 and 4 (20\% FA means T-L). In Fig. 3, under the same conditions, the T-1 cement shows the largest chemical shrinkage, followed by the T-1P cement. The T-L cement had the smallest chemical shrinkage. However, if the chemical shrinkage data (volume) are expressed in milliliter per gram of cement, as shown in Fig. 4, the chemical shrinkage of the $\mathrm{T}-1$ cement is the smallest, with the T-1P cement the largest. Part of the reason for this is that the $\mathrm{T}-1 \mathrm{P}$ cement is finer than the T-1 cement and also the fly ash contained in the T-1P cement can accelerate the cement hydration process. Due to the fineness and homogeneous distribution, the fly ash in the T-1P cement could be more active than in the T-L cement.

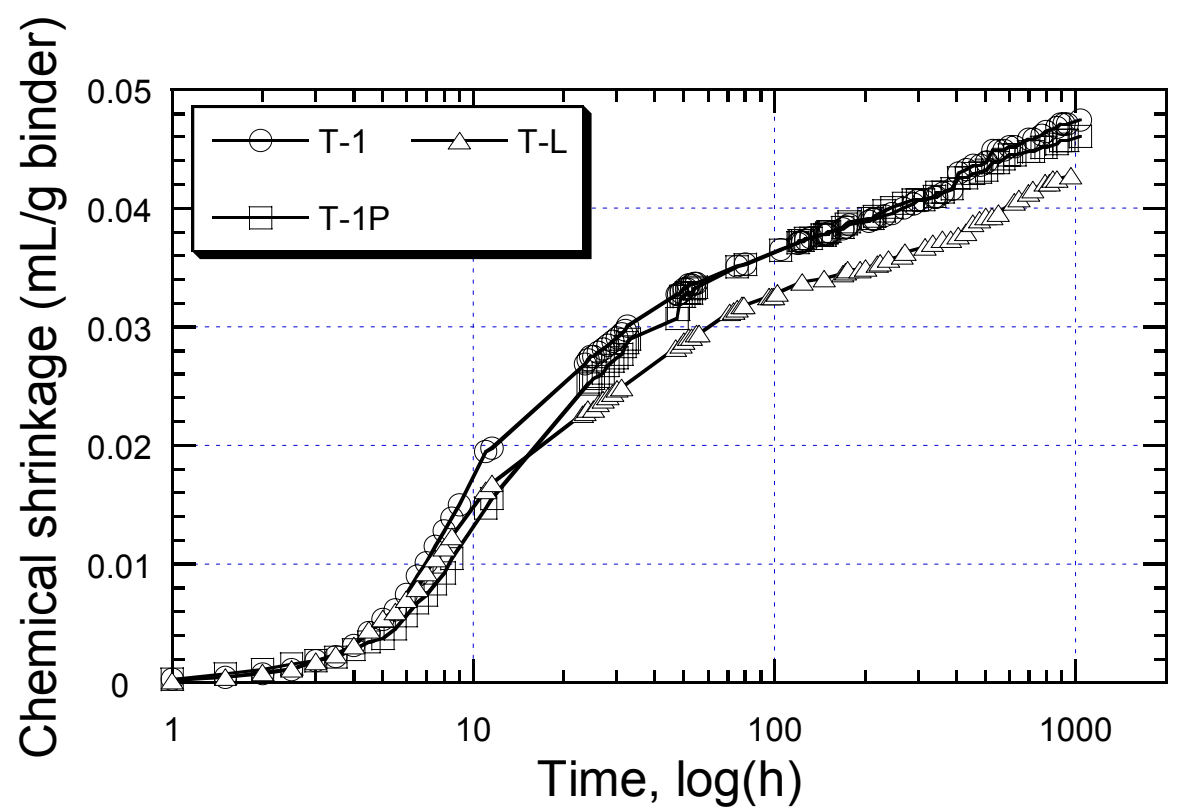

Figure 3. Chemical shrinkage results for various cements, $w / c=0.3$ 


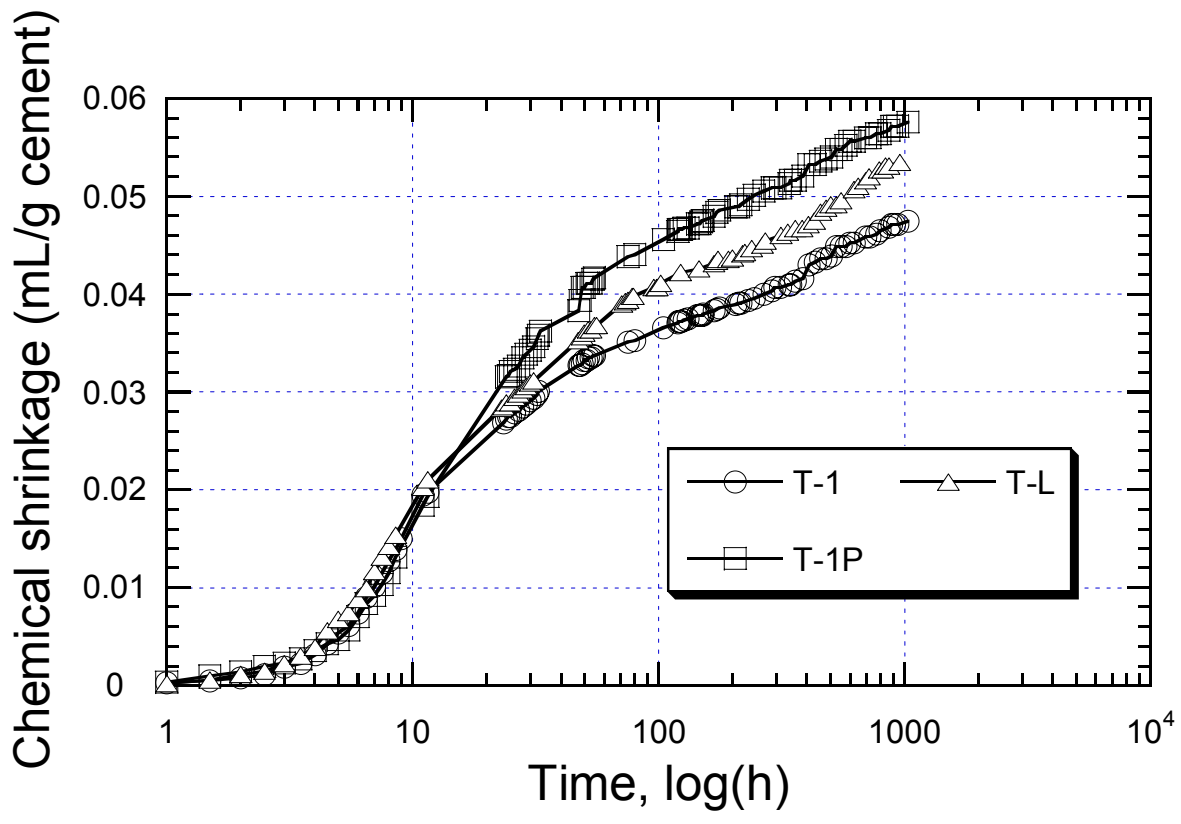

Figure 4. Chemical shrinkage results shown as $\mathrm{mL}$ per gram of cement.

The v2.0 VCCTL software was used to simulate the chemical shrinkage results of the T-1 and T$1 \mathrm{P}$ cement pastes. (Note that the fly ash experimental data was used to build the fly ash results into the VCCTL software, providing the required software tool of this project.) Results are provided in Figs. 5 and 6. The values of the parameter B used to convert from computational hydration cycles to real time were in both cases equal to 0.00032 [1]. However, after about $50 \mathrm{~h}$ of hydration, the experimental results begin to fall below the model predictions in both cases, suggesting only the early-time chemical shrinkage can be employed in evaluating the goodness of fit between model and experiment. This was also an indication to us that the implementation of fly ash consumption in the CEMYD3D model was possibly overreacting the fly ash. The chemical shrinkage results lumped all the chemical shrinkage together, so it was not possible to use these data to elucidate this possible problem. However, using SEM-based point counting enabled us to zero in on this problem by being able to measure individual phase consumption rates. 


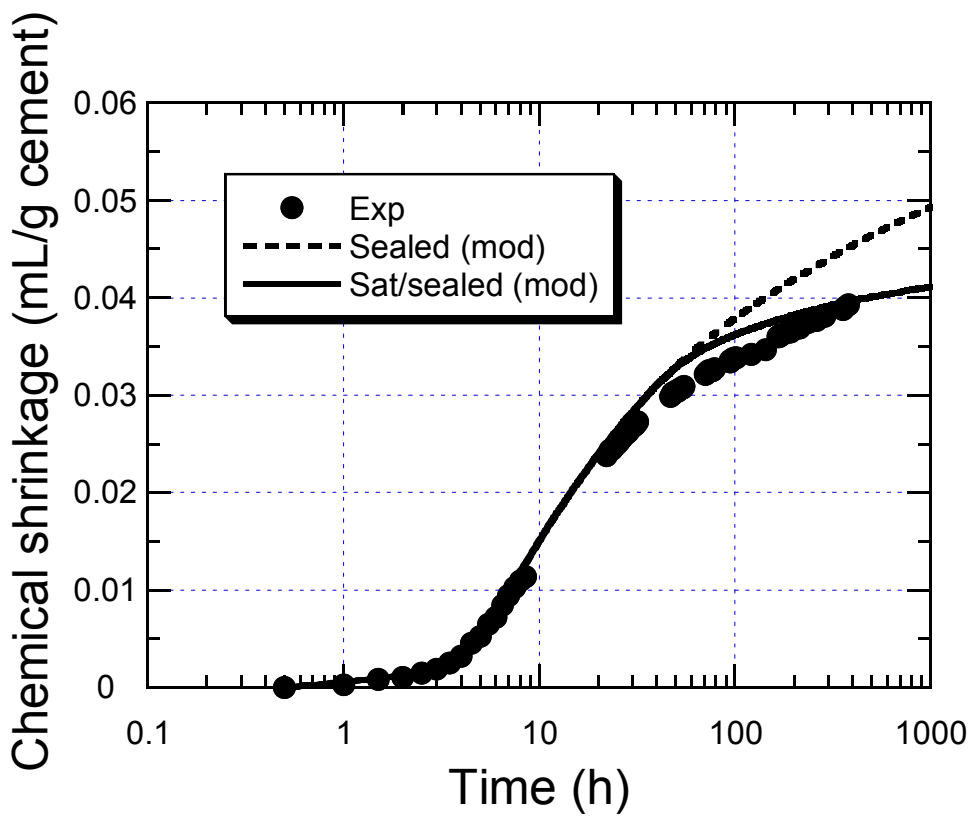

Figure 5. Experimental results (data points) and model predictions (lines) for $\mathrm{w} / \mathrm{c}=0.3 \mathrm{~T}-1$ cement.

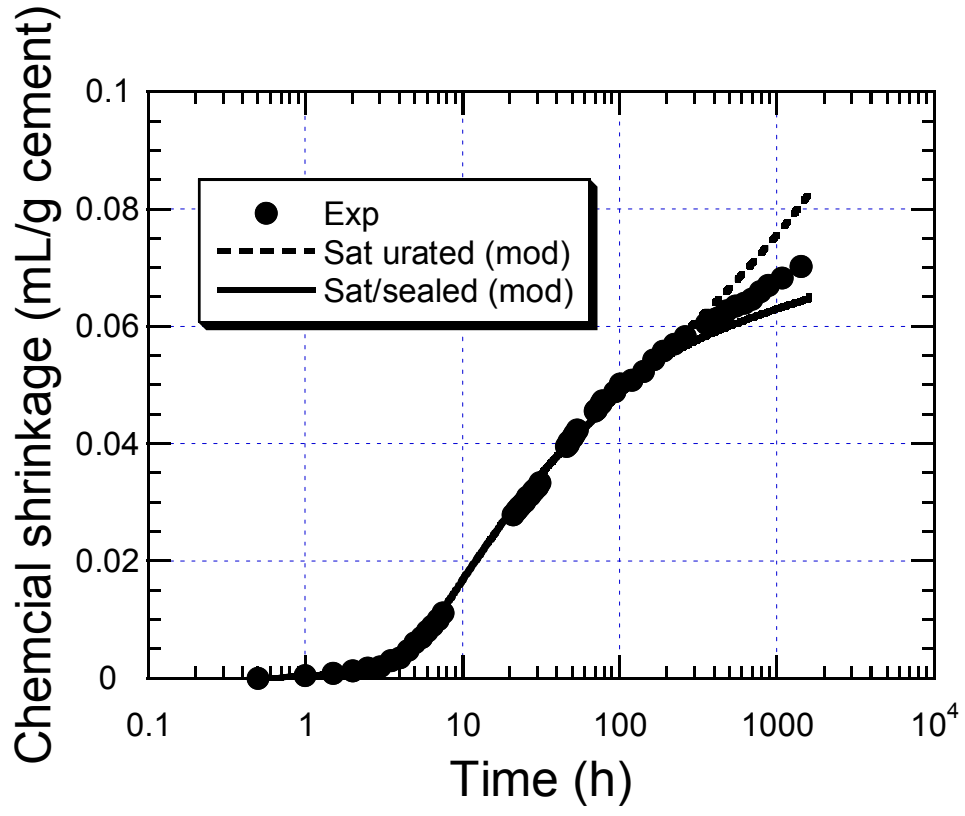

Figure 6. Experimental results (data points) and model predictions (lines) for $\mathrm{w} / \mathrm{s}=0.3 \mathrm{~T}-1 \mathrm{P}$ cement . 


\subsection{Degree of hydration by LOI and SEM}

A simple way to measure the degree of hydration of portland-cement-only cement pastes is performed using loss on ignition (LOI). A mass difference is measured between a sample dried at $100{ }^{\circ} \mathrm{C}$, and the same sample ignited at $1000{ }^{\circ} \mathrm{C}$ in an oven. The mass difference is attributed to chemically bound water loss. Knowing the relevant reactions, and the full amount of chemically bound water at $100 \%$ hydration, allows one to extract a value of $\alpha$, the degree of hydration, from the LOI measurement. The uncertainty in this measurement comes mainly from computing the full amount of chemically bound water at $100 \%$ hydration and is estimated at $2 \%$.

Measuring the degree of hydration of portland cement in the presence of a mineral admixture like fly ash is not an easy task. The amount of water loss at full hydration is not known, and the equations of reaction are not precise enough to be able to extract a value of $\alpha$ for the LOI measurements. In order to quantitatively compare to model results, however, a value of degree of hydration is needed. In addition, the CEMHYD3D model can give the extent of reaction of any phase present in the cement. So if the extent of reaction of the fly ash phase, along with the degree of hydration of the portland cement could be measured, it would provide a very sensitive check on model predictions, as well as providing the information needed to eventually be able to compare predictions for the formation factor.

Therefore a SEM-based point counting technique was developed. Details, including estimates of uncertainty, can be found elsewhere [10]. The basic idea of the method is simple: to measure the amount of cement and fly ash left after a given time of hydration. Knowing how much should have been there before hydration started allows one to quantitatively calculate how much has been consumed.

To test this technique, the degree of hydration of the plain portland cement paste (T-1) was determined by both the LOI measurement and the SEM-based point-counting technique. After this technique was validated, the degree of hydration of the cement in the blended cement pastes and the extent of reaction of the fly ash could then be estimated by the point-counting technique.

The results for the fly ash system are shown in Table 3. The top portion of the table shows the comparison between LOI and point counting results for the plain cement. The lower half of the table shows the degree of hydration of the cement phase in the blended cement pastes, as measured by point counting, and the extent of reaction of the fly ash phase (actually more than one phase but treated as one phase in this measurement) measured the same way (Frac. Reacted FA means the volume fraction of the fly ash phase). In this case, the regression equations relating LOI and point counting results in the plain cement data were also used to convert the degree of hydration of the cement phase in the blended cement pastes to the equivalent LOI results. This converted LOI data will be used as the input for modeling. Further discussion of these results is found in [10]. We want to emphasize that the lower half of Table 3, containing the fly ash consumption results, is unique (and very useful) data, the collection of which was made possible by this project. 
Table 3. Degree of hydration for plain cement and fly ash blended cement system

\begin{tabular}{|c|c|c|c|c|}
\hline & \multicolumn{2}{|c|}{ T-1 w./c=0.4 } & \multicolumn{2}{c|}{ T-1 w/c=0.5 } \\
\hline age & $\alpha$ LOI & $\alpha$ SEM & $\alpha$ LOI & $\alpha$ SEM \\
\hline $3 \mathrm{~d}$ & 0.5386 & 0.5218 & 0.5771 & 0.5521 \\
\hline $7 \mathrm{~d}$ & 0.6000 & 0.5481 & 0.7083 & 0.6608 \\
\hline $14 \mathrm{~d}$ & 0.6428 & 0.6286 & 0.7412 & 0.6992 \\
\hline $28 \mathrm{~d}$ & 0.6684 & 0.6418 & 0.7708 & 0.7461 \\
\hline $60 \mathrm{~d}$ & 0.6858 & 0.6870 & 0.7707 & 0.7723 \\
\hline $90 \mathrm{~d}$ & 0.7156 & 0.6722 & 0.8015 & 0.7836 \\
\hline
\end{tabular}

\begin{tabular}{|c|c|c|c|c|c|c|}
\hline & \multicolumn{3}{|c|}{ T-L w/s=0.4 } & \multicolumn{3}{c|}{ T-L w/s=0.5 } \\
\hline age & $\alpha$ cement $\alpha$ LOI equiv. Frac reacted FA & $\alpha$ cement $\alpha$ LOI equiv. & Frac. Reacted FA \\
\hline $3 \mathrm{~d}$ & 0.5594 & 0.5897 & 0.0347 & 0.5560 & 0.5952 & 0.0380 \\
\hline $7 \mathrm{~d}$ & 0.6293 & 0.6535 & 0.0636 & 0.6559 & 0.6860 & 0.0741 \\
\hline $14 \mathrm{~d}$ & 0.7289 & 0.7443 & 0.0723 & 0.7425 & 0.7648 & 0.0971 \\
\hline $28 \mathrm{~d}$ & 0.7426 & 0.7568 & 0.1099 & 0.7750 & 0.7943 & 0.1431 \\
\hline $60 \mathrm{~d}$ & 0.7628 & 0.7752 & 0.1532 & 0.8195 & 0.8348 & 0.1857 \\
\hline $90 \mathrm{~d}$ & 0.7861 & 0.7964 & 0.2053 & 0.8400 & 0.8534 & 0.2416 \\
\hline
\end{tabular}

\subsection{Pore solution press and conductivity measurement}

Concrete and cement paste are porous materials, with pores ranging from nanometer to millimeter sizes. The left over mixing water, which partially or fully saturates these pores, is full of ions from dissolved cement chemical species. In fact, it is very alkaline, with a $\mathrm{pH}$ of around 13. Any diffusive transport of chloride ions through concrete must go through these pores. The composition of the ions already present in the pore fluid will greatly affect the speed at which the dissolved chlorides will diffuse through the pores. Therefore, as part of the model-building process, it is crucial that the actual composition of the ions in the pore fluid be measured so that the hydration and transport models can be properly calibrated.

To get water out of a saturated sponge, one simply squeezes the sponge and the water oozes out. Cement paste is essentially a sponge, but with a much more rigid solid backbone and pores that are much smaller and less well-connected than in a typical sponge. So to squeeze out the pore fluid requires a pressure of over $690 \mathrm{MPa}$ (100 $000 \mathrm{psi}$ ), which can only be supplied by a mechanical loading machine [12]. A special jig is needed to hold and confine the cement paste under such high pressures. The setup for pore solution extraction is shown in Fig. 7. Samples made for the pore solution press were diameter $50 \mathrm{~mm} \times$ height $100 \mathrm{~mm}$ cylinders. Samples were cast following the same procedures described in the previous section. After being cured for various ages, the samples were used for pore solution extraction. Figure 8 shows two such cylindrical samples after pore fluid extraction. Notice the shortened height, since the samples 
were axially compressed under very high load. The $7 \mathrm{~d}$ sample is shorter than the $28 \mathrm{~d}$ sample, because the $7 \mathrm{~d}$ sample has a lower stiffness and lower confined compressive strength. After extraction, the pore solutions were immediately diluted by deionized water and then analyzed by ion chromatography, shown in Fig. 9.

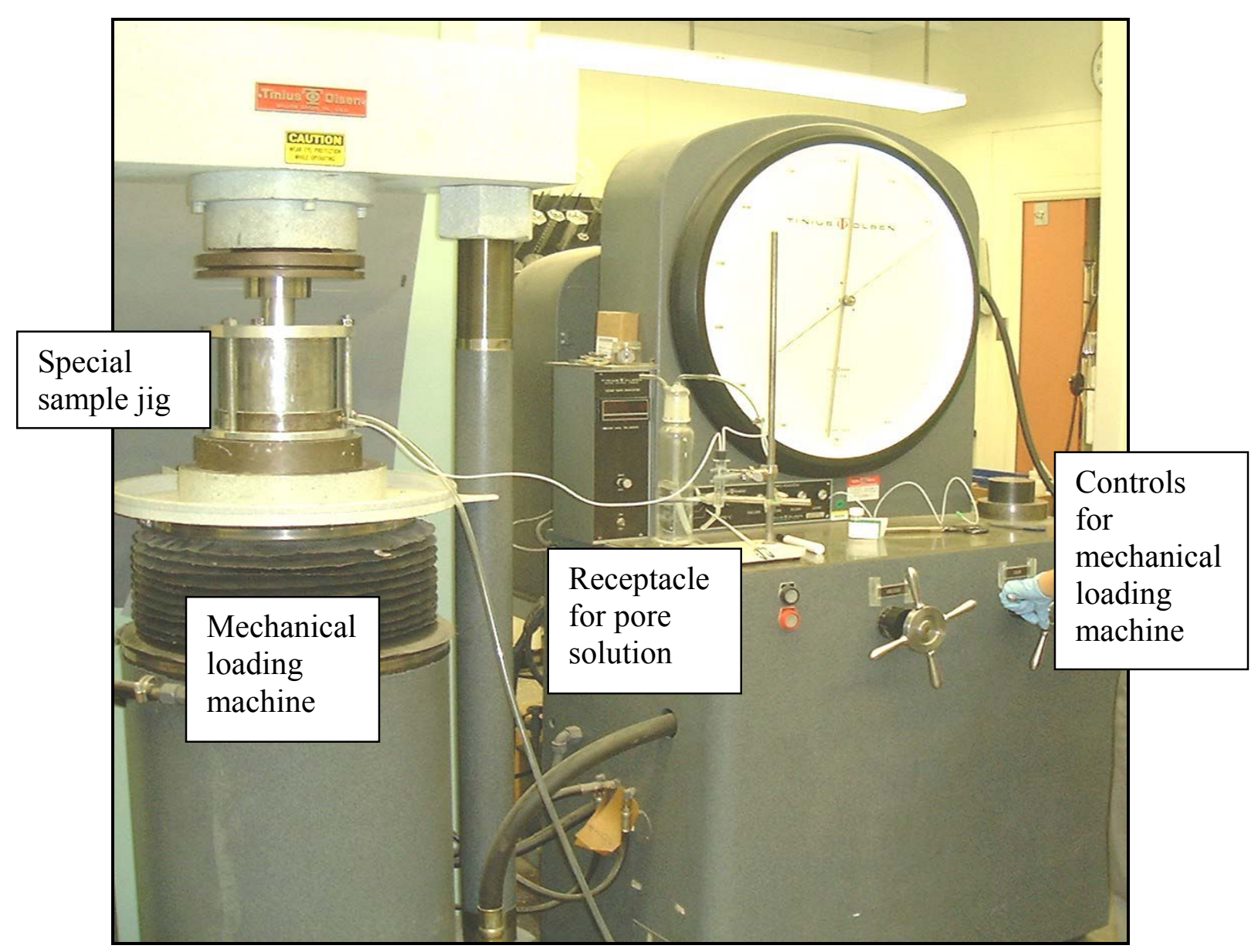

Figure 7. Setup for the pore solution extraction 


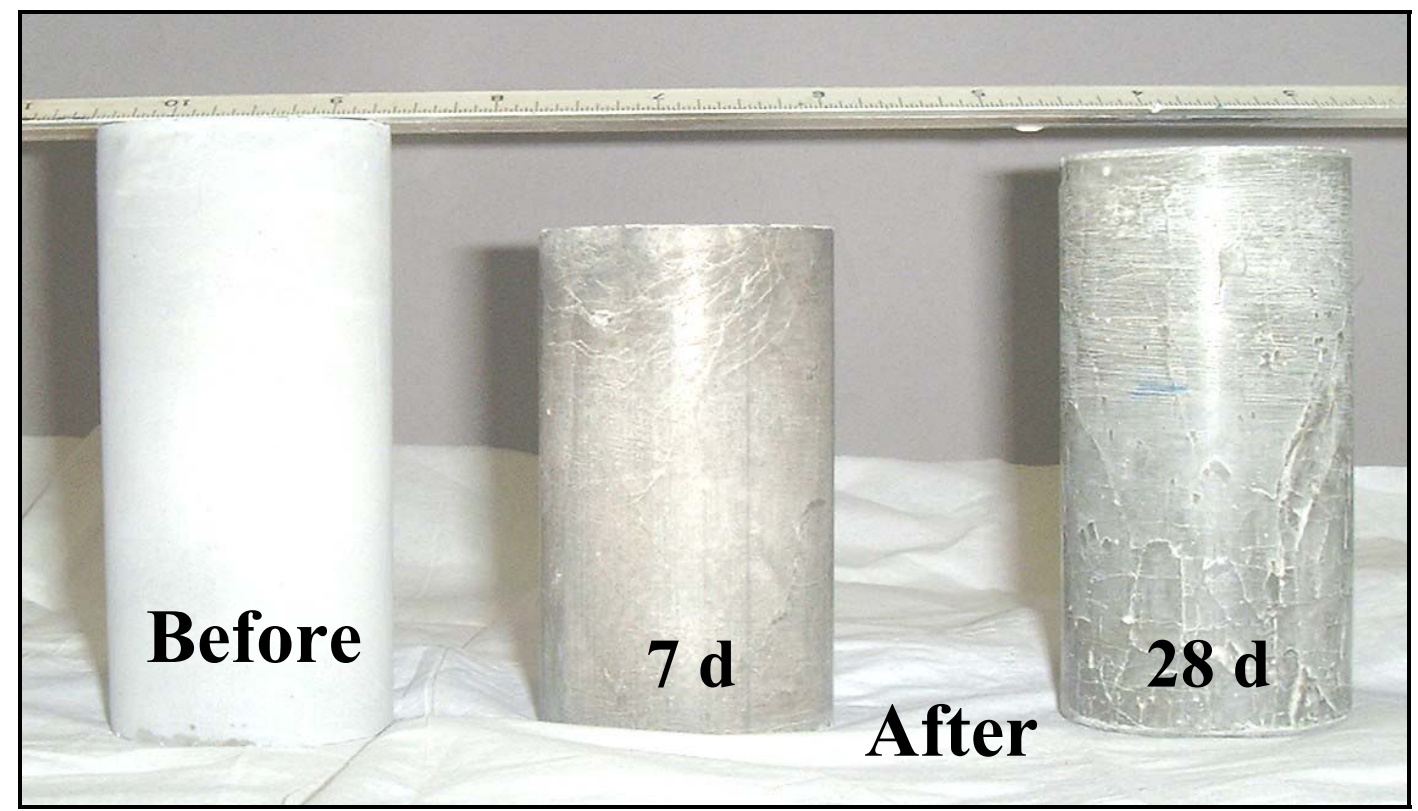

Figure 8 . Showing one cylinder before pore extraction, and two cylinders ( $7 \mathrm{~d}$ and $28 \mathrm{~d}$ ) after pore fluid extraction. 


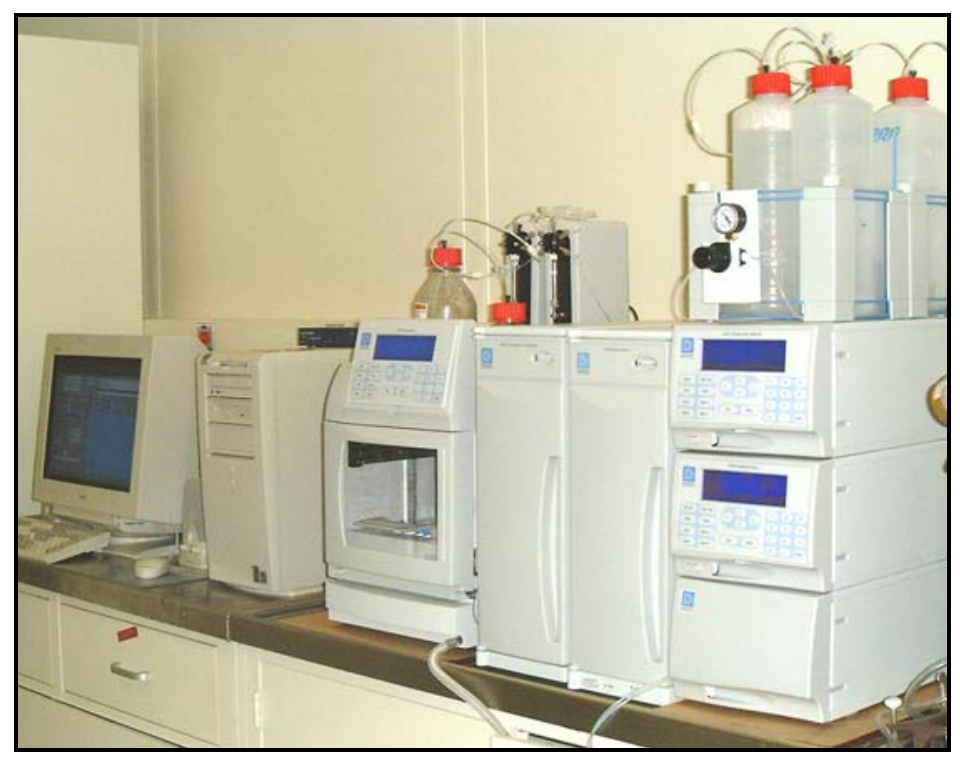

Figure 9. Ion Chromatography system

The test machine shown in Fig. 7 was not able to apply a high enough load to force the pore solution out at later ages, with a maximum load of only $440 \mathrm{kN}$, so a larger testing machine was used, with loads up to $1.5 \mathrm{MN}$. This higher load was successful in forcing out enough pore solution at later ages so that an ion chromatography measurement of the ionic concentrations in the pore solution could be made.

Ion chromatography was used only to measure the $\left[\mathrm{Na}^{+}\right]$and $\left[\mathrm{K}^{+}\right]$concentrations, along with the associated $\left[\mathrm{OH}^{-}\right]$concentration. To avoid carbonation problems, and to give enough fluid for an accurate measurement, the conductivity of artificial pore fluid, with the same $\left[\mathrm{Na}^{+}\right]$and $\left[\mathrm{K}^{+}\right]$ concentrations, was measured. Previous work had shown this to be an accurate method [13], so that only knowledge of the $\left[\mathrm{Na}^{+}\right]$and $\left[\mathrm{K}^{+}\right]$concentrations, and corresponding $\left[\mathrm{OH}^{-}\right]$ concentration, is enough to accurately predict the pore solution conductivity. The data in Table 4 include the age of the cement paste at pore solution extraction, the $\left[\mathrm{Na}^{+}\right]$and $\left[\mathrm{K}^{+}\right]$concentrations, and the conductivity of the pore fluid, $\sigma_{f}$. Note that these are sealed systems, so they tend to have higher ionic concentrations than saturated systems. Also note that the T-1P and T-L cements give similar results. 
Table 4. Conductivity and compositions of pore solutions for fly ash system (ion concentrations are given in $\mathrm{mol} / \mathrm{L}$ )

\begin{tabular}{|c|c|c|c|c|c|c|c|}
\hline \multicolumn{4}{|c|}{$\mathrm{T}-1 \mathrm{w} / \mathrm{c}=0.5$} & \multicolumn{4}{|c|}{$\mathrm{T}-1 \mathrm{w} / \mathrm{c}=0.4$} \\
\hline Age & {$[\mathrm{Na}]$} & {$[\mathrm{K}]$} & C sol (S/m) & Age & {$[\mathrm{Na}]$} & {$[\mathrm{K}]$} & C sol (S/m) \\
\hline $3 d$ & 0.0935 & 0.4048 & 10.35 & $3 d$ & 0.1327 & 0.6306 & 15.09 \\
\hline $7 d$ & 0.1112 & 0.4575 & 11.63 & $7 \mathrm{~d}$ & 0.1588 & 0.7300 & 17.21 \\
\hline $14 \mathrm{~d}$ & 0.1163 & 0.4873 & 12.26 & $14 \mathrm{~d}$ & 0.1716 & 0.7410 & 17.59 \\
\hline $28 \mathrm{~d}$ & 0.1198 & 0.4929 & 12.42 & $28 \mathrm{~d}$ & 0.1918 & 0.7629 & 18.08 \\
\hline $56 \mathrm{~d}$ & 0.1208 & 0.5203 & 12.94 & $56 \mathrm{~d}$ & 0.1975 & 0.7838 & 18.7 \\
\hline $90 \mathrm{~d}$ & 0.1242 & 0.5279 & 13.13 & $90 \mathrm{~d}$ & 0.2094 & 0.7994 & 19.14 \\
\hline \multicolumn{4}{|c|}{$\mathrm{T}-1 \mathrm{P} \mathrm{w} / \mathrm{s}=0.5$} & \multicolumn{4}{|c|}{$\mathrm{T}-1 \mathrm{P} \mathrm{w} / \mathrm{s}=0.4$} \\
\hline Age & {$[\mathrm{Na}]$} & {$[\mathrm{K}]$} & C sol (S/m) & Age & {$[\mathrm{Na}]$} & {$[\mathrm{K}]$} & C sol (S/m) \\
\hline $3 d$ & 0.0987 & 0.3445 & 9.29 & $3 d$ & 0.1322 & 0.5003 & 12.76 \\
\hline $7 d$ & 0.1129 & 0.3768 & 10.15 & $7 d$ & 0.1318 & 0.5716 & 14.03 \\
\hline $14 \mathrm{~d}$ & 0.1079 & 0.3527 & 9.61 & $14 \mathrm{~d}$ & 0.1383 & 0.5868 & 14.41 \\
\hline $28 \mathrm{~d}$ & 0.1211 & 0.3987 & 10.7 & $28 d$ & 0.1406 & 0.5989 & 14.66 \\
\hline $60 \mathrm{~d}$ & 0.1238 & 0.4163 & 11.08 & $60 \mathrm{~d}$ & 0.1495 & 0.6427 & 15.56 \\
\hline $90 \mathrm{~d}$ & 0.1266 & 0.4419 & 11.6 & $90 \mathrm{~d}$ & 0.1549 & 0.6637 & 16.01 \\
\hline \multicolumn{4}{|c|}{$T-L \mathrm{w} / \mathrm{s}=0.5$} & \multicolumn{4}{|c|}{$T-L$ w/s $=0.4$} \\
\hline Age & {$[\mathrm{Na}]$} & {$[\mathrm{K}]$} & C sol (S/m) & Age & {$[\mathrm{Na}]$} & {$[\mathrm{K}]$} & C sol (S/m) \\
\hline $3 d$ & 0.0787 & 0.3136 & 8.35 & $3 d$ & 0.1011 & 0.4307 & 10.97 \\
\hline $7 d$ & 0.0874 & 0.3478 & 9.16 & $7 d$ & 0.1347 & 0.4449 & 11.79 \\
\hline $14 \mathrm{~d}$ & 0.0941 & 0.3526 & 9.37 & $14 d$ & 0.1217 & 0.4618 & 11.88 \\
\hline $28 d$ & 0.1057 & 0.3645 & 9.8 & $28 d$ & 0.1255 & 0.4844 & 12.36 \\
\hline $56 \mathrm{~d}$ & 0.1205 & 0.3961 & 10.64 & $56 \mathrm{~d}$ & 0.1304 & 0.5263 & 13.2 \\
\hline $90 \mathrm{~d}$ & 0.1234 & 0.4264 & 11.26 & $90 \mathrm{~d}$ & 0.1355 & 0.5612 & 13.91 \\
\hline
\end{tabular}

The uncertainty in both ionic concentrations and measured conductivity is less than \pm 1 in the last digit. The main component of uncertainty lies in the actual pore fluid extraction process. The question is - are we getting the actual pore fluid that is in the interior of the specimen? Is the pore fluid that we collect the same as the pore fluid that was squeezed out of the sample? These are very real questions, and we have come to the conclusion that the pore fluid that we extract is not the same as the pore fluid that is in the specimen. Consider the plain cement pastes made with T-1 cement, no fly ash. Figures 10 and 11 show the concentration of potassium and sodium vs. time as measured by experiment, and as predicted by the CEMHYD3D (VCCTL) hydration model. More importantly, the curves marked "sealed" and "saturated" are theoretical estimates based on the known total amount of alkalis (sodium and potassium minerals) in the cement. The total amount of alkalis present, along with a calculation of the porosity present in the cement paste, give an upper bound estimate for the pore solution concentrations. "Saturated" means saturated curing, with the sample embedded in water that can supply the amount used up in hydration. "Sealed" means sealed curing, where the only water available to the hydrating cement is that mixed originally with the cement. Our samples underwent sealed curing, so these curves are the more appropriate for comparison with the experimental results. Note that in Fig. 10, both 
the $\left[\mathrm{K}^{+}\right]$and $\left[\mathrm{Na}^{+}\right]$ion concentrations are at or above the theoretical maxima for sealed curing. In Fig. 11, at a higher w/c value, the experimental values are slightly below the theoretical maxima. So the $\mathrm{w} / \mathrm{c}=0.4$ values are definitely not trustworthy. After careful analysis, we reached the conclusion that the experiments were done properly, but the technique as performed in this study was inadequate, especially at lower w/c values where the amount of fluid collected is very small because of a combination of the stiffness of the sample and its lower porosity.

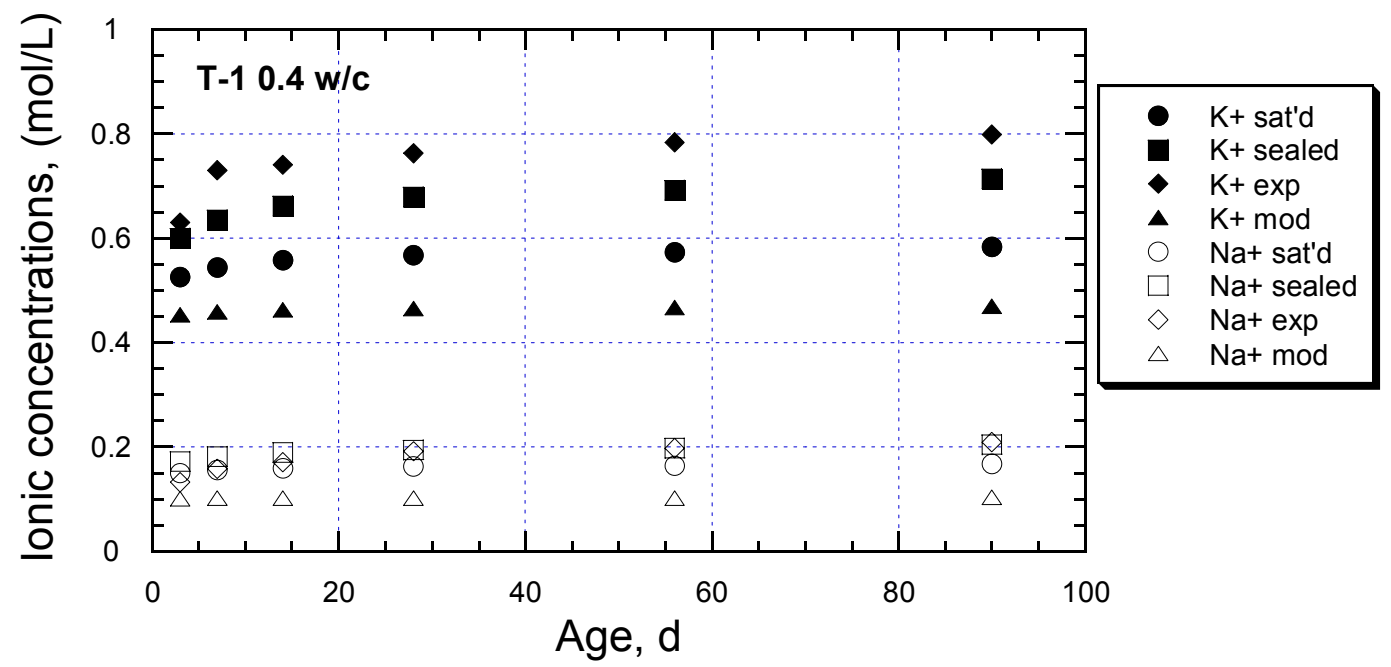

Figure 10: Concentration of $\left[\mathrm{K}^{+}\right]$and $\left[\mathrm{Na}^{+}\right]$ions vs. time for the $\mathrm{T}-1$ cement, $\mathrm{w} / \mathrm{c}=0.4$, using experimental measurements (exp), theoretical maximum estimates (saturated and sealed curing conditions), and direct predictions from the CEMHYD3D software (mod) for sealed curing conditions.

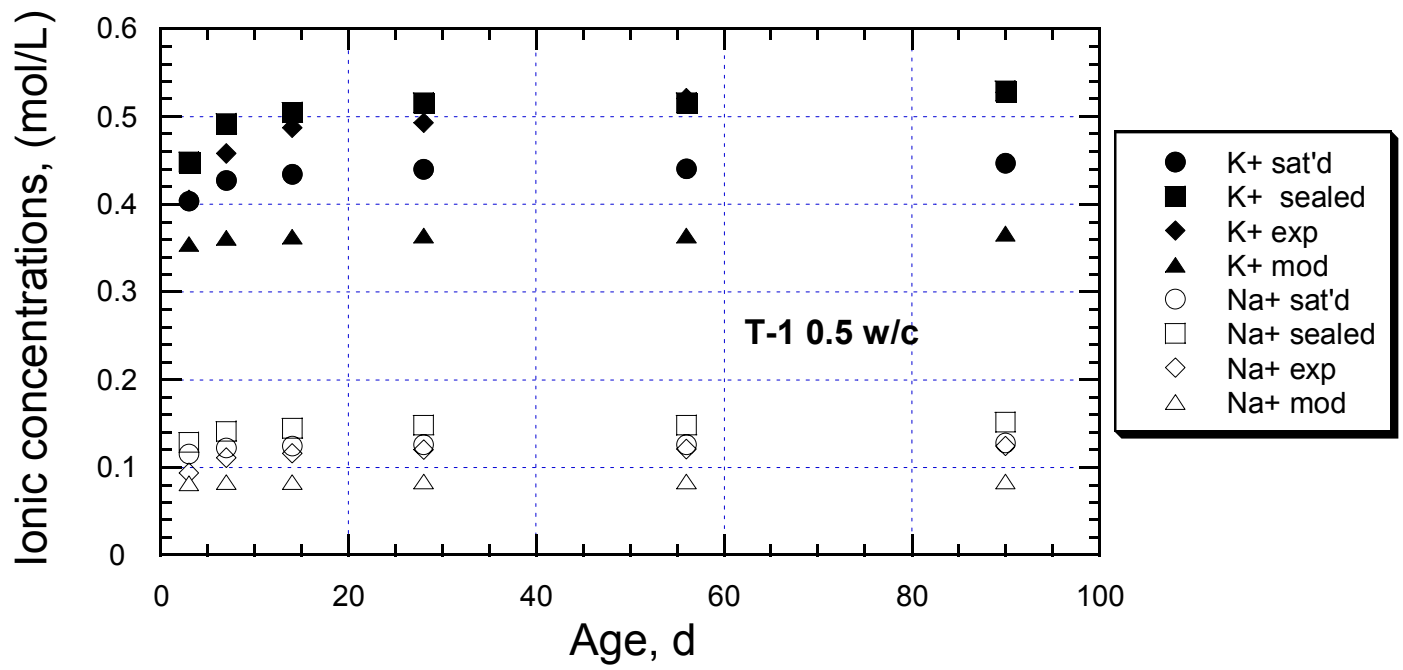

Figure 11: Concentration of $[\mathrm{K}+]$ and $\left[\mathrm{Na}^{+}\right]$ions vs. time for the $\mathrm{T}-1$ cement, $\mathrm{w} / \mathrm{c}=0.5$, using experimental measurements (exp), theoretical maximum estimates (saturated and sealed curing 
conditions), and direct predictions from the CEMHYD3D software (mod) for sealed curing conditions.

\subsection{Bulk conductivity}

Samples for bulk conductivity measurements were diameter $37.5 \mathrm{~mm} \times$ height $37.5 \mathrm{~mm}$ cylinders. Samples were cast following similar procedures as above. The reason for the sealed curing conditions was to protect the samples from ions leaching from the samples and changing the pore solution concentrations. We desired the pore solution samples and the bulk conductivity samples to have the same pore solution, and different leaching conditions for the two sets of samples would destroy this equality. Sealed curing conditions seemed like the only possible solution. Unfortunately, especially for the $\mathrm{w} / \mathrm{c}=0.4$ samples, sealed curing created unsaturated conditions in the pore space, so that subsequent exposure to water will draw water into the pore space. Up to $25 \%$ of the pore space can be unsaturated under these conditions. After being cured for various ages, samples were cut into thin slices approximately $3 \mathrm{~mm}$ to $4 \mathrm{~mm}$ thick. Three discs at the same age were cut from three different cylinders cast at the same time. The bulk conductivity of a paste at a given age was calculated as the average of the three discs. In order to reduce the loss of the pore solution during the cutting process, an alkali solution with $0.1 \mathrm{~mol} / \mathrm{L}$ $\mathrm{KOH}$ and $0.05 \mathrm{~mol} / \mathrm{L} \mathrm{NaOH}$ was used instead of methanol as a cutting lubricant. Exposure to this solution will also change the pore solution by the drawing in of this solution into the pore space. After cutting, the specimens were washed by the same cutting solution and kept in a sealed plastic bag to keep in the moisture. The thickness was measured by using a digital caliper before the bulk conductivity measurement, taking at least eight readings around the diameter, and the average was used as the disc thickness.

The bulk conductivity was measured by the divided-cell method (see Fig. 12). Two cells with different lengths were employed in the project. Both divided cell effective diameters were 25.4 $\mathrm{mm}(1 \mathrm{in})$, and thus the specimen area tested was $5.0654 \cdot 10^{-4} \mathrm{~m}^{2}$. But before the cell could be used to measure bulk conductivity, the cell constant for each cell had to be measured. To measure the cell constant, two standard $\mathrm{KCl}$ solutions, at $0.1 \mathrm{~mol} / \mathrm{L}$ and $0.01 \mathrm{~mol} / \mathrm{L}$ concentration, were prepared. The conductivities of the two solutions were $12.8246 \mathrm{~S} / \mathrm{m}$ and $1.40823 \mathrm{~S} / \mathrm{m}$. The cells were filled with the solution and clamped together (without any sample in the middle), and connected to an impedance spectrometer to measure the true DC resistance (Fig. 13). The cell constant was calculated as follows:

$$
\frac{L}{A}=\sigma \times R
$$

where L/A is the cell constant, in $\mathrm{m}^{-1}, \sigma$ is the conductivity of the solution in the cell, in $\mathrm{S} / \mathrm{m}$, and $\mathrm{R}$ is the measured resistance, in ohms. The cell constant of the longer divided-cell was found to be $505.78 \mathrm{~m}^{-1}$, and a value of $317.976 \mathrm{~m}^{-1}$ was found for the shorter one used.

Cement paste sample discs were clamped between the two cells. The cells then were filled with 
$0.1 \mathrm{~mol} / \mathrm{L} \mathrm{KOH}$ and $0.05 \mathrm{~mol} / \mathrm{L} \mathrm{NaOH}$ solutions, with a total conductivity of $3.414 \mathrm{~S} / \mathrm{m}$. The cell was connected to the impedance spectrometer, which was used to determine the true DC resistance of each disc. The bulk conductivity was calculated as follows:

$$
\begin{gathered}
R_{0}=\frac{\left(\frac{L}{A}\right) \times 100}{\sigma_{0}} \\
R_{\mathrm{b}}=R_{\mathrm{t}}-R_{0} \\
\sigma_{b}=\frac{L_{b}}{R_{b} \times A}
\end{gathered}
$$

where $\mathrm{L} / \mathrm{A}$ is the cell constant $\left(\mathrm{m}^{-1}\right), \sigma_{0}=3.414 \mathrm{~S} / \mathrm{m}$ is the conductivity of the solution in the cell, $\mathrm{R}_{0}$ is the resistance of the solution-filled, which varies from cell to cell $(\Omega), \mathrm{R}_{t}$ is the measured resistance from impedance spectroscopy $(\Omega), \mathrm{R}_{\mathrm{b}}$ is the resistance for the bulk cement paste $(\Omega)$, $\sigma_{b}$ is the bulk conductivity of the cement paste $(\mathrm{S} / \mathrm{m}), \mathrm{L}_{\mathrm{b}}$ is the thickness of the cement paste disc (m), and $A$ is the effective specimen area tested $\left(5.0654 \cdot 10^{-4} \mathrm{~m}^{2}\right.$ in the current study). Since sealed curing created unsaturated conditions in the pore space, the exposure to the ionic solution serving as electrodes in the divided cell apparatus will draw this fluid into the pore space. Up to $25 \%$ of the pore space can be unsaturated under these conditions, so up to this amount could have the conductivity of the divided cell apparatus solution. This will be taken into account in subsequent modeling predictions. The saturated curing, which was found to be necessary in order to avoid pore fluid leaching during curing, unfortunately complicated the actual pore fluid solution during bulk conductivity measurement. Some work was carried out to see whether or not the samples could all be independently saturated with a known ionic solution, but this was found to be impractical - it took too long and was unreliable.

If the measured pore solution conductivity was a reliable indication of the pore solution actually present inside the sample, the formation factor for each cement paste disc would be calculated by dividing the conductivity of pore solution by the bulk conductivity:

$$
F=\frac{\sigma_{p}}{\sigma_{b}}
$$

where $F=$ formation factor, $\sigma_{\mathrm{b}}=$ conductivity of the bulk cement paste in $\mathrm{S} / \mathrm{m}$, and $\sigma_{\mathrm{p}}=$ pore solution conductivity in $\mathrm{S} / \mathrm{m}$. 
We limit ourselves to bulk conductivity measurements. Table 5 contains all the experimental data, averaged over three samples each, for the bulk conductivity of the T-1 and T-L systems. Based on the findings that the T-1P system was not much different from the T-L system, except for finer particle size, we only carried out conductivity measurements on the T-L and T-1 systems.

Table 5: Bulk conductivity, $\sigma_{\mathrm{b}}$, for T-1 and T-L systems

\begin{tabular}{|c|c|c|c|}
\hline \multicolumn{2}{|c|}{$\mathrm{T}-1 \mathrm{w} / \mathrm{c}=0.4$} & \multicolumn{2}{|c|}{$\mathrm{T}-1 \mathrm{w} / \mathrm{c}=0.5$} \\
\hline age & $\sigma_{b}(\mathrm{~S} / \mathrm{m})$ & Age & $\sigma_{b}(S / m)$ \\
\hline $3 \mathrm{~d}$ & 0.1404 & $3 \mathrm{~d}$ & 0.2239 \\
\hline $7 \mathrm{~d}$ & 0.1195 & $7 \mathrm{~d}$ & 0.1537 \\
\hline $14 \mathrm{~d}$ & 0.1150 & $14 \mathrm{~d}$ & 0.1402 \\
\hline $28 \mathrm{~d}$ & 0.0955 & $28 \mathrm{~d}$ & 0.1274 \\
\hline $60 \mathrm{~d}$ & 0.0895 & $60 \mathrm{~d}$ & 0.1307 \\
\hline $90 \mathrm{~d}$ & 0.0770 & $90 \mathrm{~d}$ & 0.0923 \\
\hline \multicolumn{2}{|c|}{$\mathrm{T}-\mathrm{L} \mathrm{w} / \mathrm{s}=0.4$} & \multicolumn{2}{|c|}{$\mathrm{T}-\mathrm{L} \mathrm{w} / \mathrm{s}=0.5$} \\
\hline age & $\sigma_{b}(S / m)$ & Age & $\sigma_{b}(S / m)$ \\
\hline $3 \mathrm{~d}$ & 0.2514 & $3 \mathrm{~d}$ & 0.2916 \\
\hline $7 \mathrm{~d}$ & 0.1500 & $7 \mathrm{~d}$ & 0.2604 \\
\hline $14 \mathrm{~d}$ & 0.1367 & $14 \mathrm{~d}$ & 0.2296 \\
\hline $28 \mathrm{~d}$ & 0.1110 & $28 \mathrm{~d}$ & 0.1814 \\
\hline $60 \mathrm{~d}$ & 0.0732 & $60 \mathrm{~d}$ & 0.1231 \\
\hline $90 \mathrm{~d}$ & 0.0564 & $90 \mathrm{~d}$ & 0.0759 \\
\hline
\end{tabular}




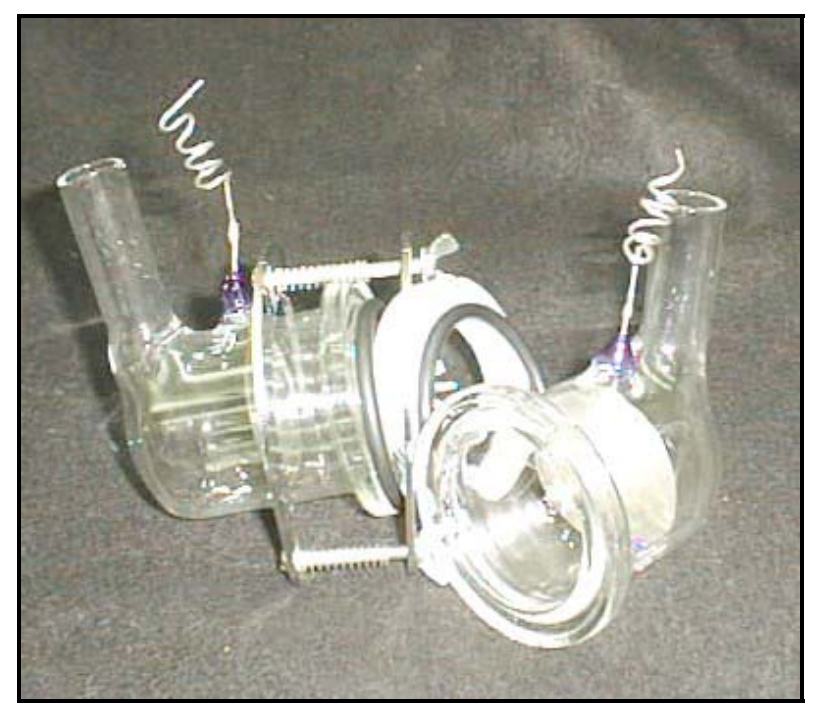

Figure 12. Divided-cell apparatus used for the bulk conductivity measurement.

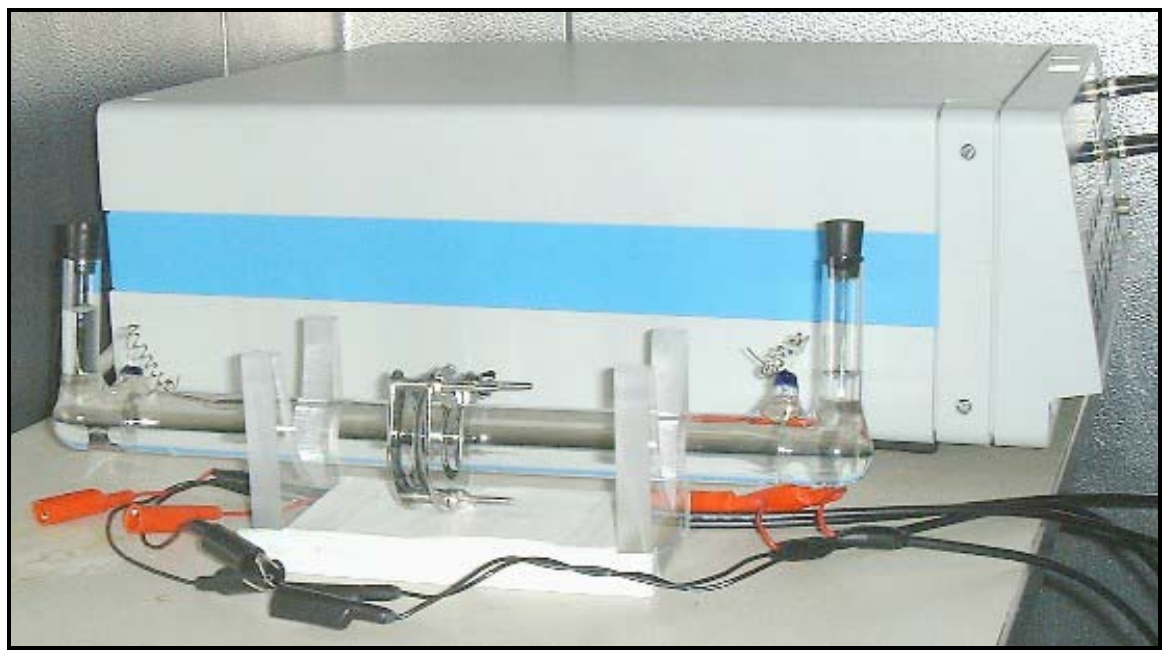

Figure 13. Setup for the bulk conductivity measurement (impedance spectrometer)

\section{Modeling}

\subsection{Three dimensional microstructures for cement clinkers}

The T-1, T1-P, and fly ash were analyzed using scanning electron microscope (SEM) techniques 
that NIST has developed [14]. These techniques go beyond simple particle size distribution measurements, by showing how the different chemical phases of cement are distributed among the different size particles. To prepare a polished specimen for viewing in the SEM, approximately $25 \mathrm{~g}$ of the powder to be imaged is blended with an epoxy resin to form an extremely viscous paste. The resin/powder mixture is pressed into a small cylindrical mold and cured at $60^{\circ} \mathrm{C}$ for $24 \mathrm{~h}$. The cured specimen is then cut and polished to obtain a plane surface for imaging. The composite X-ray images for the various materials are shown in Figs. 14 and 15. These images will be used in generating 3-D microstructures and model predictions for cement properties in later research.

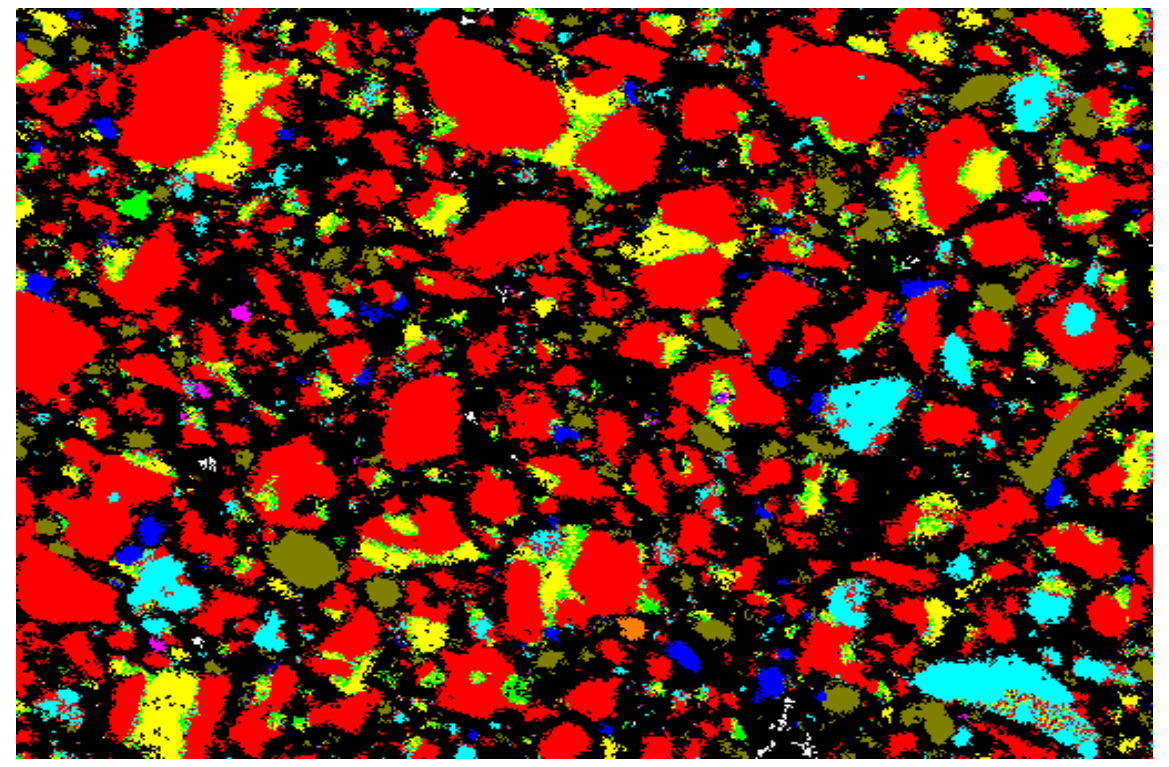

Figure 14. Processed image of the T-1 cement ( $500 \mathrm{X}-256 \mu \mathrm{m}$ by $200 \mu \mathrm{m})$. Red is $\mathrm{C}_{3} \mathrm{~S}$, aqua is $\mathrm{C}_{2} \mathrm{~S}$, green is $\mathrm{C}_{3} \mathrm{~A}$, yellow is $\mathrm{C}_{4} \mathrm{AF}$, and pale green is gypsum (the main minerals found in portland cement). 


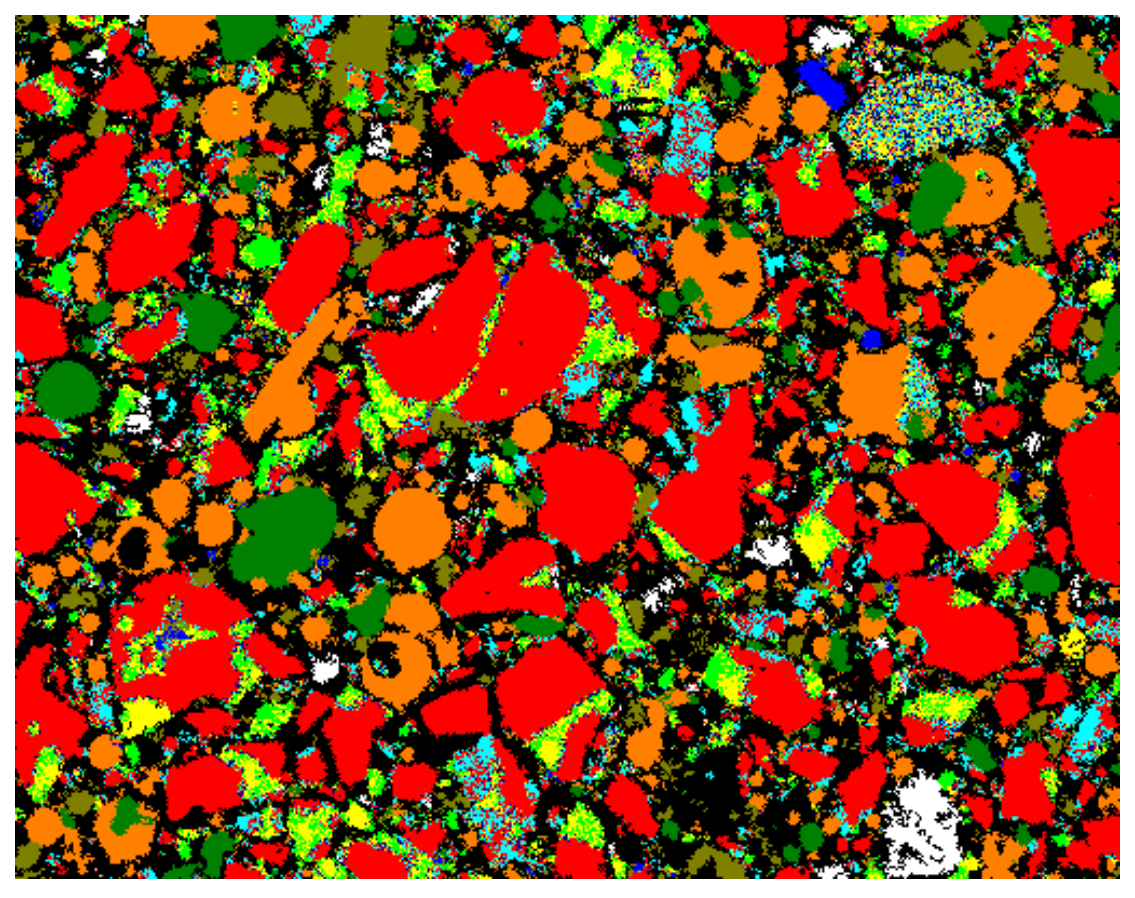

Figure 15. Processed image of the T-1P blended cement $(500 \mathrm{X}-256 \mu \mathrm{m}$ by $200 \mu \mathrm{m})$. Red is $\mathrm{C}_{3} \mathrm{~S}$, aqua is $\mathrm{C}_{2} \mathrm{~S}$, green is $\mathrm{C}_{3} \mathrm{~A}$, yellow is $\mathrm{C}_{4} \mathrm{AF}$, and pale green is gypsum (the main minerals in portland cement). The orange particles are fly ash, although some of the orange particles are not particularly round, as is usual for fly ash, which may be a result of the intergrinding process. White is free lime, dark green is silica, and dark blue is calcium aluminosilicate.

\subsection{Degree of hydration and fly ash reaction modeling}

The cement and particle size distribution (PSD) files in the prediction of degree of hydration can be reached at the following files in VCCTL Version 2:

\begin{tabular}{|l|l|l|}
\hline Cement & Cement file & $\begin{array}{l}\text { Particle } \\
\text { microstructure file }\end{array}$ \\
\hline T-1 w/c $=0.4$ & T1h040b & Pt1h040a.img \\
\hline T-1 w/c $=0.5$ & T1h050b & T1h050.psd \\
\hline T-L w/s $=0.4$ & T1hfa040c & Pt1hfa040.img \\
\hline T-L w/s $=0.5$ & T1hfa050c & Pt1hfa050.img \\
\hline
\end{tabular}

The cement hydration model works via cycles of dissolution, diffusion, and reaction - see Ref. [1] for more details. The number of model cycles is related, nonlinearly, to the actual time of reaction. 
Table 6: Age, number of model cycles, and model degrees of hydration for T-1 cements. The number of model cycles were chosen so as to closely match the experimentally determined degree of hydration.

\begin{tabular}{|c|c|c|}
\hline $\mathrm{w} / \mathrm{c}=0.4$ & Cycles & $\alpha$ (model) \\
\hline 3 & 388 & 0.539 \\
\hline 7 & 529 & 0.6 \\
\hline 14 & 770 & 0.643 \\
\hline 28 & 1042 & 0.668 \\
\hline 60 & 1370 & 0.686 \\
\hline 90 & 2347 & 0.716 \\
\hline \multicolumn{3}{|c|}{} \\
\hline $\mathrm{w} / \mathrm{c}=0.5$ & Cycles & $\alpha$ (model) \\
\hline 3 & 354 & 0.5771 \\
\hline 7 & 604 & 0.7083 \\
\hline 14 & 711 & 0.7412 \\
\hline 28 & 839 & 0.7708 \\
\hline 60 & 839 & 0.7707 \\
\hline
\end{tabular}

For orientation purposes, Table 6 shows the amount of model hydration cycles needed to achieve a certain level of cement hydration in the T-1 plain cement system. The point of this project was to be able to extend this model into fly-ash blended cements. For that reason, the following figures, as well as Table 7, show the degree of hydration vs. time, both model and experiment, for the cement in the fly ash systems, as well as the fraction reacted of the fly ash vs. the cement degree of hydration for the same systems. This experimental data for the fly ash system is unique. By checking against it, we found that the model was definitely overreacting fly ash phases - at a given degree of cement hydration, the model had much too large of an extent of reaction of the fly ash phases compared to experiment. The scientific details of what was done to improve the model and make it more realistic (reaction theory, etc.) are to be found elsewhere [15]. In the following graphs, which display results of the corrected model, one sees both the reasonably good fit of model vs. experiment for the degree of hydration of the cement vs. time, which we had before, and the extent of reaction of the fly ash vs. the degree of hydration of the cement phase, which is now much improved from earlier work. There is not perfect agreement between model and experiment, but one must remember that the uncertainty in the experimental data points is about \pm 0.04 (absolute), so that there is approximate agreement within experimental uncertainty. Having good agreement with both the degree of hydration of the cement simultaneously with the extent of reaction of the mineral admixture means that the model is more likely producing an accurate blended cement paste microstructure. 


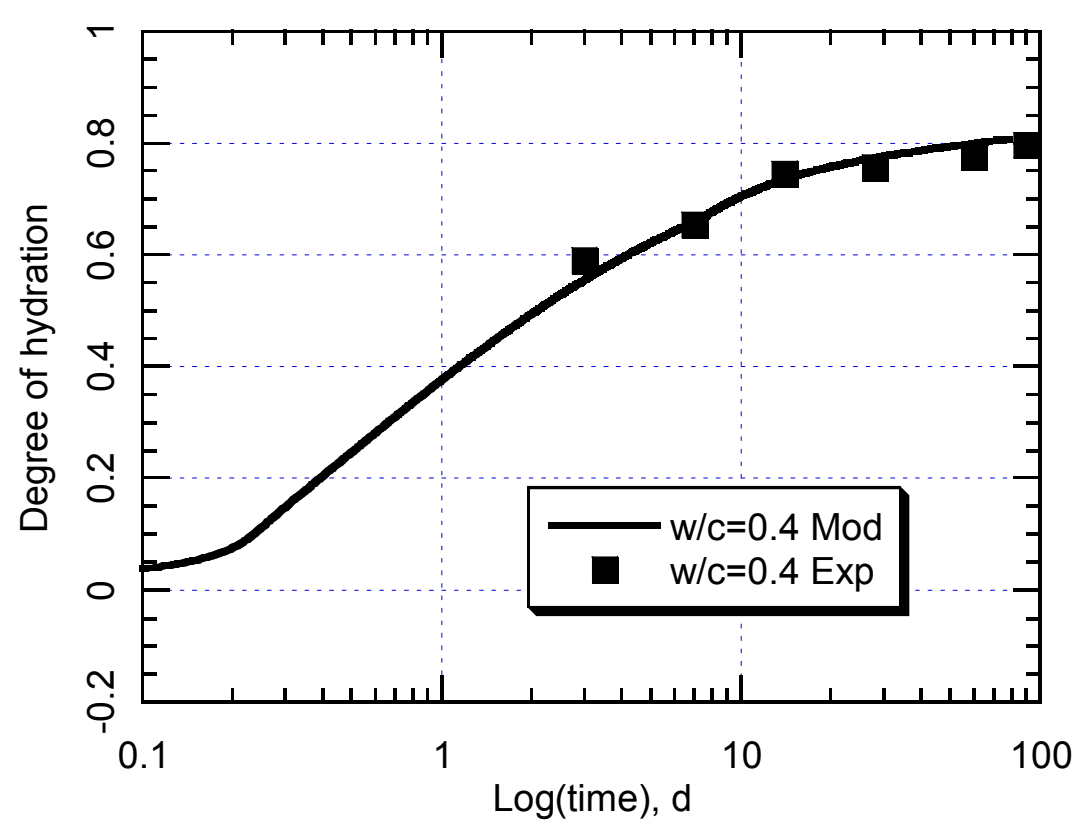

Figure 16. Degree of hydration of the cement in T-L, w/s $=0.4$

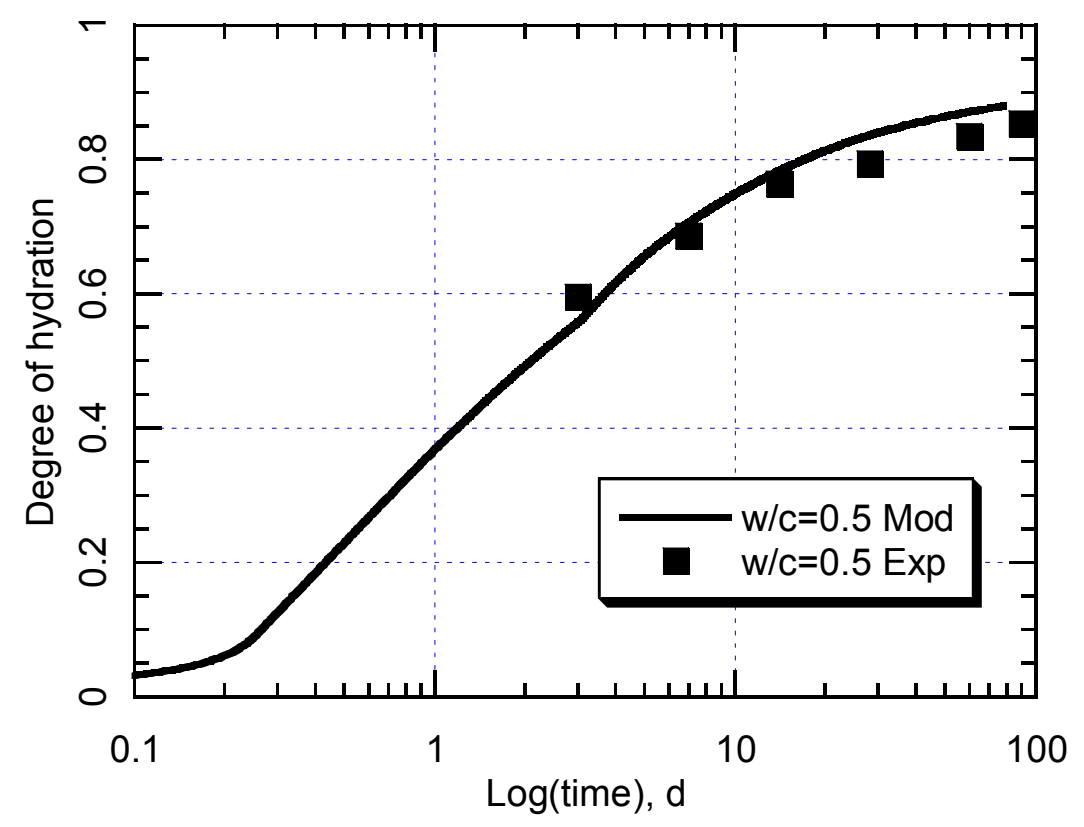

Figure 17. Degree of hydration of the cement phase in T-L, w/s $=0.5$ 


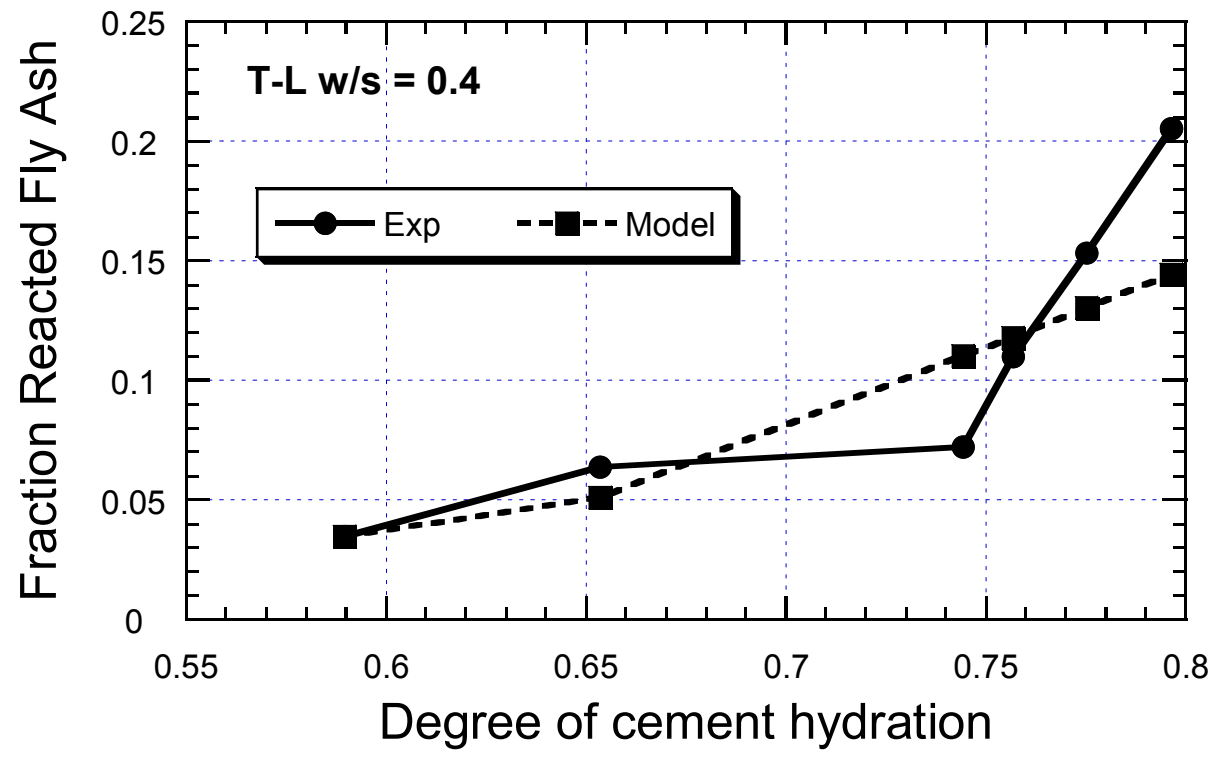

Figure 18. Fraction reacted of the fly ash phase in $\mathrm{T}-\mathrm{L}, \mathrm{w} / \mathrm{s}=0.4$

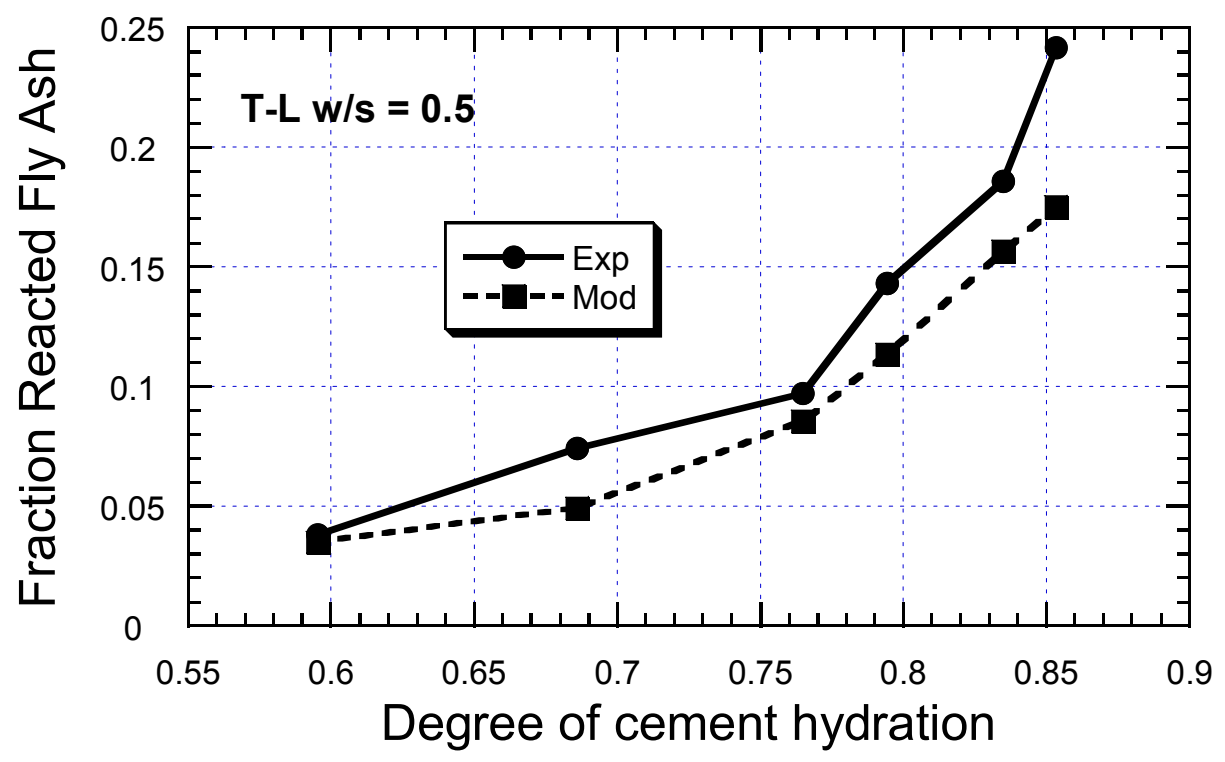

Figure 19. Fraction reacted of the fly ash phase in T-L, w/s $=0.5$ 
Table 7: Age, number of model cycles, and model degrees of cement hydration and fraction reacted of fly ash for T-L cements. The number of model cycles was chosen so as to closely match the experimentally determined degree of hydration.

\begin{tabular}{|c|c|c|c|c|}
\hline $\mathrm{w} / \mathrm{c}=0.4$ & Cycles & $\alpha($ model $)$ & $\begin{array}{l}\text { Fraction Reacted } \\
\text { (exp) }\end{array}$ & $\begin{array}{c}\text { Fraction Reacted } \\
\text { (model) }\end{array}$ \\
\hline 3 & 398 & 0.5897 & 0.0347 & 0.0346 \\
\hline 7 & 519 & 0.6535 & 0.0636 & 0.05101 \\
\hline 14 & 926 & 0.7443 & 0.0723 & 0.11007 \\
\hline 28 & 1046 & 0.7568 & 0.1099 & 0.1179 \\
\hline 60 & 1272 & 0.7752 & 0.1532 & 0.1303 \\
\hline 90 & 1663 & 0.7964 & 0.2053 & 0.1443 \\
\hline $\mathrm{w} / \mathrm{c}=0.5$ & Cycles & $\alpha$ (model) & $\begin{array}{l}\text { Fraction Reacted } \\
\text { (exp) }\end{array}$ & $\begin{array}{c}\text { Fraction Reacted } \\
\text { (model) }\end{array}$ \\
\hline 3 & 386 & 0.5952 & 0.038 & 0.035 \\
\hline 7 & 556 & 0.686 & 0.0741 & 0.0492 \\
\hline 14 & 812 & 0.7648 & 0.0971 & 0.0856 \\
\hline 28 & 955 & 0.7943 & 0.1431 & 0.1134 \\
\hline 60 & 1230 & 0.8348 & 0.1857 & 0.1564 \\
\hline 90 & 1397 & 0.8534 & 0.2416 & 0.1751 \\
\hline
\end{tabular}

\subsection{Conductivity modeling}

\subsubsection{Determination of the conductivity of regular CSH for T-1 and T-L cements}

A relative conductivity for regular $\mathrm{C}-\mathrm{S}-\mathrm{H}$ of 0.005 provides the best fit to the experimental data, for the T-1 cement, in the absence of fly ash. This was determined by running the conductivity code, for a range of cement paste microstructures, with different conductivity values for the C-S$\mathrm{H}$ phase. It was scaled so that the pore solution conductivity in the capillary pores was 1 . The uncertainty in the conductivity value for the C-S-H phase is probably of the order of $100 \%$, as its value can vary widely without changing the predicted bulk conductivity that much for $\mathrm{w} / \mathrm{c}=$ 0.4 and $\mathrm{w} / \mathrm{c}=0.5$ cement pastes. This same value of 0.005 was found to hold, within a similarly large uncertainty, for the pozzolanic C-S-H that was formed from reaction of the silica in fly ash with the calcium hydroxide phase in the cement paste.

\subsubsection{Results of conductivity modeling for $T-1$}

A fitted value of relative conductivity (relative to the pore solution) for the regular C-S-H that comes from cement hydration is enough to proceed to compute values of the bulk conductivity for the plain (T-1) cement pastes and compare them to experimental data. Table 8 shows the modeling results for the bulk conductivity for the T-1 cement systems. There is reasonably good 
agreement, within uncertainty, between experiment and model results. Note that model computes the cement paste conductivity relative to the pore solution having a conductivity of unity. A separate part of CEMHYD3D computes the principal ionic concentrations $([\mathrm{K}+],[\mathrm{Na}+]$, and $[\mathrm{OH}-])$, from which a prediction of pore solution conductivity, $\sigma_{\mathrm{p}}$, is made [13]. Then, following the equation for $F$, the formation factor, one gets the bulk conductivity by $\sigma_{b}=(1 / F) \sigma_{p}$.

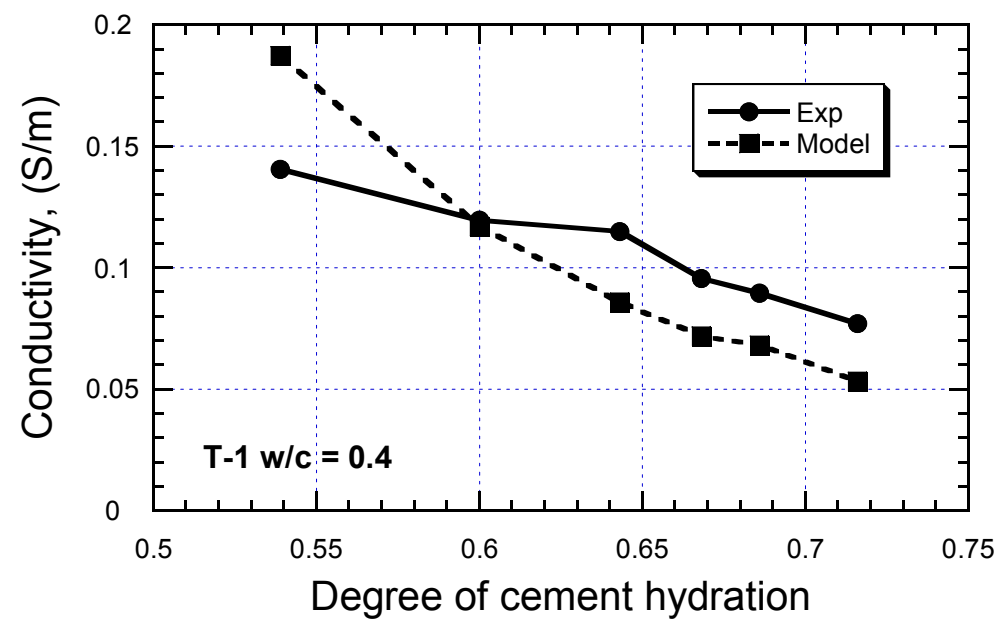

Figure 20. The experimental and modeling values of the bulk conductivity found for the T-1 $\mathrm{w} / \mathrm{c}=0.4$ cement pastes.

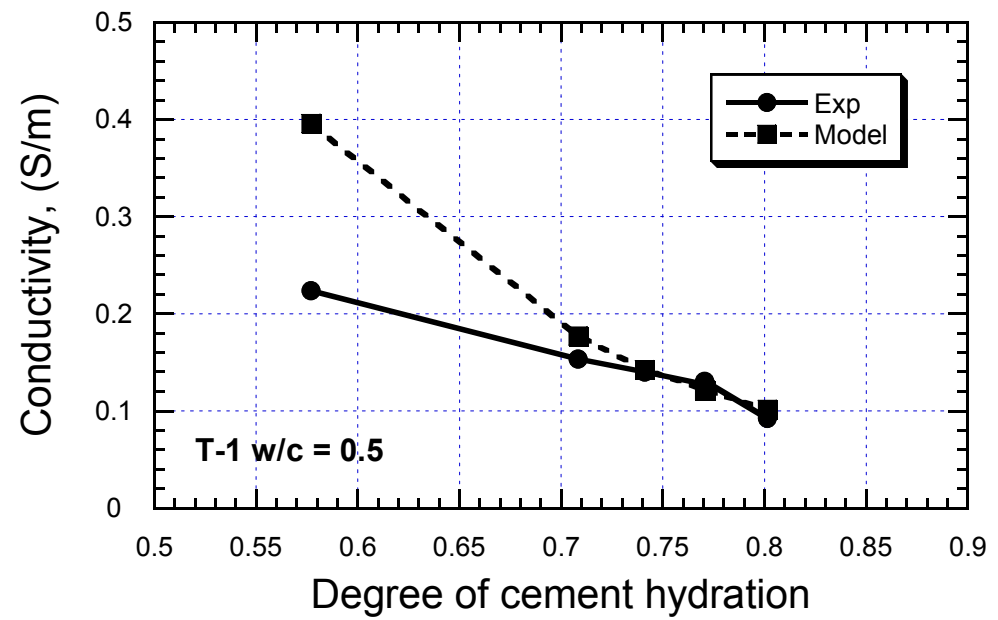

Figure 21. The experimental and modeling values of the bulk conductivity found for the T-1 $\mathrm{w} / \mathrm{c}=0.5$ cement pastes. 
Table 8: Bulk conductivity data, experiment and model, for T-1 cement. The uncertainty in the bulk conductivity is about \pm 1 in the least significant figure. The uncertainty in the model data is larger, about $10 \%$ of the total value.

\begin{tabular}{|c|c|c|}
\hline $\begin{array}{c}\text { Degree of } \\
\text { cement } \\
\text { hydration }\end{array}$ & $\begin{array}{c}\text { Bulk } \\
\text { conductivity }- \\
\text { exp }\end{array}$ & $\begin{array}{c}\text { Bulk } \\
\text { conductivity }- \\
\text { model }\end{array}$ \\
\hline \multicolumn{3}{|c|}{$\mathrm{T}-1 \mathrm{w} / \mathrm{c}=0.4$} \\
\hline 0.539 & 0.1404 & 0.187 \\
\hline 0.600 & 0.1195 & 0.117 \\
\hline 0.643 & 0.1150 & 0.0858 \\
\hline 0.668 & 0.09550 & 0.0719 \\
\hline 0.686 & 0.08950 & 0.0681 \\
\hline 0.716 & 0.07700 & 0.0533 \\
\hline \multicolumn{3}{|c|}{$\mathrm{T}-1 \mathrm{w} / \mathrm{c}=0.5$} \\
\hline 0.577 & 0.2239 & 0.396 \\
\hline 0.708 & 0.1537 & 0.177 \\
\hline 0.741 & 0.1402 & 0.142 \\
\hline 0.771 & 0.1274 & 0.122 \\
\hline 0.771 & 0.1307 & 0.122 \\
\hline 0.802 & 0.09230 & 0.102 \\
\hline
\end{tabular}

\subsubsection{Results of conductivity modeling for $T-L$}

Table 9 shows the modeling results for the bulk conductivity for the T-L cement/fly ash systems. Note that model computes the cement paste conductivity relative to the pore solution having a conductivity of unity. A separate part of CEMHYD3D computes the principal ionic concentrations $([\mathrm{K}+],[\mathrm{Na}+]$, and $[\mathrm{OH}-])$, from which a prediction of pore solution conductivity, $\sigma_{\mathrm{p}}$, is made [13]. Then, following the equation for $\mathrm{F}$, the formation factor, one gets the bulk conductivity by $\sigma_{\mathrm{b}}=(1 / F) \sigma_{\mathrm{p}}$. Conductivities were only computed when the predicted value of fly ash reaction was within $25 \%$ of the experimental measurement, which explains some of the missing data points in the third column of Table 9 . Figures 22 and 23 display the same information graphically. There is rough agreement between experiment and model results, although probably not within uncertainty. It is difficult to tell what the model uncertainties are, although they have been estimated at $10 \%$. 


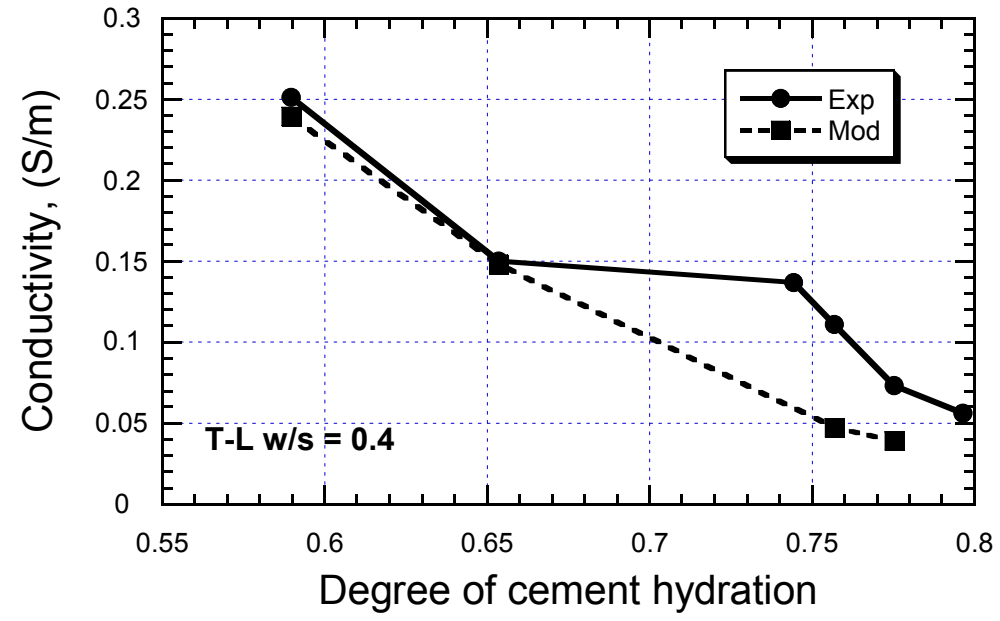

Figure 22. The experimental and modeling values of the bulk conductivity found for the T-L $\mathrm{w} / \mathrm{s}=0.4$ cement pastes.

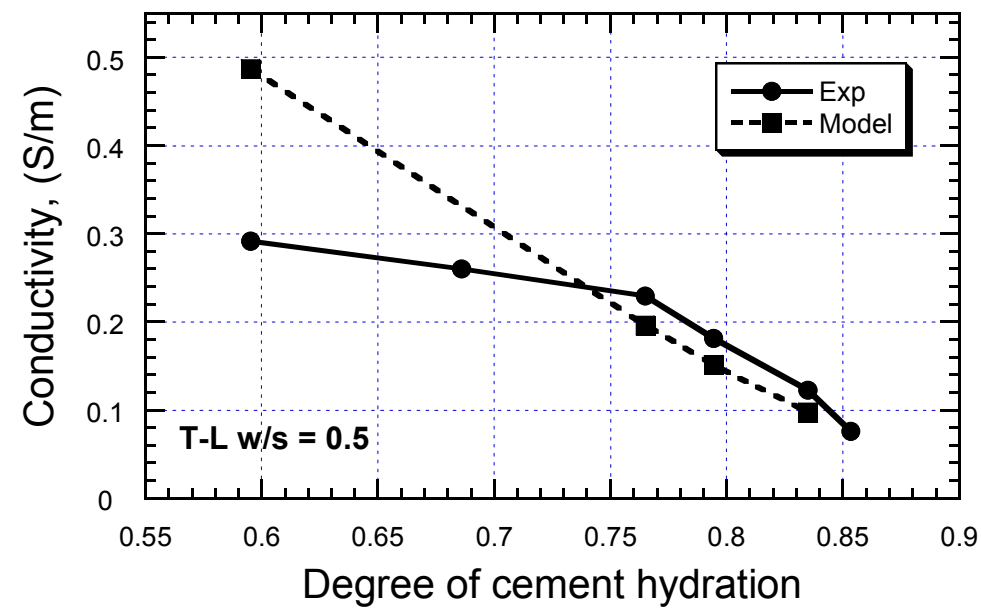

Figure 23. The experimental and modeling values of the bulk conductivity found for the T-L $\mathrm{w} / \mathrm{s}=0.5$ cement pastes. 
Table 9: Bulk conductivity data, experiment and model, for T-L cement

\begin{tabular}{|c|c|c|}
\hline $\begin{array}{l}\text { Degree of } \\
\text { cement } \\
\text { hydration }\end{array}$ & $\begin{array}{c}\text { Bulk } \\
\text { conductivity - } \\
\text { exp }\end{array}$ & $\begin{array}{c}\text { Bulk } \\
\text { conductivity - } \\
\text { model }\end{array}$ \\
\hline \multicolumn{3}{|c|}{ T-L w/s $=0.4$} \\
\hline 0.590 & 0.2514 & 0.239 \\
\hline 0.654 & 0.1500 & 0.149 \\
\hline 0.744 & 0.1367 & \\
\hline 0.757 & 0.1110 & 0.0470 \\
\hline 0.775 & 0.07320 & 0.0393 \\
\hline 0.796 & 0.05640 & \\
\hline \multicolumn{3}{|c|}{ T-L w/s $=0.5$} \\
\hline 0.595 & 0.2916 & 0.487 \\
\hline 0.686 & 0.2604 & \\
\hline 0.765 & 0.2296 & 0.197 \\
\hline 0.794 & 0.1814 & 0.152 \\
\hline 0.835 & 0.1231 & 0.0982 \\
\hline 0.853 & 0.07590 & \\
\hline
\end{tabular}

\section{Conclusions}

This project was designed to systematically incorporate a fly ash into the CEMHYD3D model and therefore into the VCCTL software. This would be a start to allowing cement manufacturers, and others, to virtually see how this waste-stream material affects the properties of concrete made with this material. The complex chemistry of these materials necessitated a unique experimental approach to be able to so incorporate them. Because of this project, which involved novel work never done before for these materials, we ended up with: (1) a new SEM-based point counting technique for measuring how fly ash (and other materials like slag), and cement in their presence, reacted over time; (2) a unique data set of individual phase reactions vs. time that can be used to check model refinements for a particular fly ash and cement; (3) greatly improved models of how these materials reacted with water and cement over time; (4) bulk conductivities vs. degree of hydration and fly ash reaction extent for cement pastes that included these materials, and (5) model predictions in reasonable agreement with experiment for cement pastes that included one kind of fly ash material.

The uncertainties found in the experimental measurements certainly propagate into the model results in the formation factor work, as the experimental formation factors were used to calibrate the conductivity assigned to the regular C-S-H and the extra C-S-H formed from the mineral 
admixture. This calibration is only necessary because we do not have a nano-scale model for the actual nano-pore structure and nano-adsorption qualities of C-S-H, from which we could accurately predict the conductivity.

However, the improved models give us a useful tool with which to address hydration up to $90 \mathrm{~d}$. The reactions of the fly ash were only measured up to $90 \mathrm{~d}$. The formation factors of the blended cements were not that much different from the plain cement pastes. It is possible that the mineral admixtures go on reacting strongly after $90 \mathrm{~d}$, so that the formation factor of the blended cement pastes would eventually be much larger than that of the plain cement pastes. This would be useful data to collect.

Doing the experimental work necessary to properly characterize one fly ash material showed us how much improved characterization techniques are necessary to be able to handle the many kinds of cement/fly ash in use in the United States today. This will be the focus of future research.

\section{Acknowledgements}

We would like to thank the EPA for partial support of this project, and specifically the direction of Heather Tansey and Vincent Camobreco of the EPA. We would also like to thank Dr. Clarissa Ferraris and Dr. Arnold Rosenberg, of NIST, for useful comments on the manuscript.

\section{References}

1) D.P. Bentz, Three-dimensional Computer Simulation of Portland Cement Hydration and Microstructure Development, J. Amer. Ceram. Soc. 80, 3-21 (1997).

2) P.J. Williams, J.J. Biernacki, L.R. Walker, JH.M. Meyer, C.J. Rawn, and J.M. Bai, Microanalysis of alkali-activated fly ash-CH pastes, Cem. Conc. Res. 32, 963-972 (2002).

3) D.P. Bentz and Sebastien Remond, Incorporation of Fly Ash into a 3-D Cement Hydration Microstructure Model NIST Internal Report 6050, Gaithersburg, Maryland, August, 1997. Also found at http://ciks.cbt.nist.gov/monograph, Part I, Chapter 4, section 2b.

4) K.A. Snyder and J. Marchand, Effects of speciation on the apparent diffusion coefficient in nonreactive porous systems, Cem. Conc. Res. 31, 1837-1845 (2001).

5) E. Samson, J. Marchand, and K.A. Snyder, Calculation of ionic diffusion coefficients on the basis of migration test results, Mater. Struct. 36, 156-165 (2003).

6) K.A. Snyder, C. Ferraris, N.S. Martys, and E.J. Garboczi, "Using impedance spectroscopy to assess the viability of the rapid chloride test for determining concrete conductivity," J. of Research NIST 105, 497-509 (2000).

7) J.C. Russ, The Image Processing Handbook (CRC Press, Boca Raton, 2002).

8) E.J. Garboczi, "Permeability, Diffusivity, and Microstructural Parameters: A Critical Review," Cement and Concrete Research 20, 591-601 (1990).

9) J.W. Bullard, ed. VCCTL 2003 Annual Report, NIST Internal Report 7096.

10) X. Feng, E.J. Garboczi, D. P. Bentz, P.E. Stutzman, and T. O. Mason, "Estimation of the 
Degree of Hydration of Blended Cement Pastes by a Scanning Electron Microscope PointCounting Procedure", to appear in Cem. Conc. Res. (2004).

11) C.F. Ferraris, V.A. Hackley, and A.I. Avilés, "Measurement of Particle Size Distribution in Portland Cement Powder: Analysis of ASTM Round-Robin Studies”, June, 2004, in press.

12) S. Diamond and R.S. Barneyback, Expression and analysis of pore fluids from hardened cement pastes and mortars, Cem. Conc. Res. 11, 279-285 (1981).

13) K.A. Snyder, X. Feng, B. Keen, and T.O. Mason, "Estimating the electrical conductivity of cement paste pore solutions from $\left[\mathrm{OH}^{-}\right],\left[\mathrm{K}^{+}\right]$and $\left[\mathrm{Na}^{+}\right]$concentrations, Cem. Conc. Res. 33, 793-798 (2003).

14) D.P. Bentz and P.E. Stutzman, SEM Analysis and Computer Modeling of Hydration of Portland Cement Particles, pp. 60-73 in Petrography of Cementitious Materials, edited by S.M. DeHayes and D. Stark (ASTM, Philadelphia, 1994).

15) J.W. Bullard, X. Feng, P.E. Stutzman, and D.P. Bentz, in preparation (2004). 